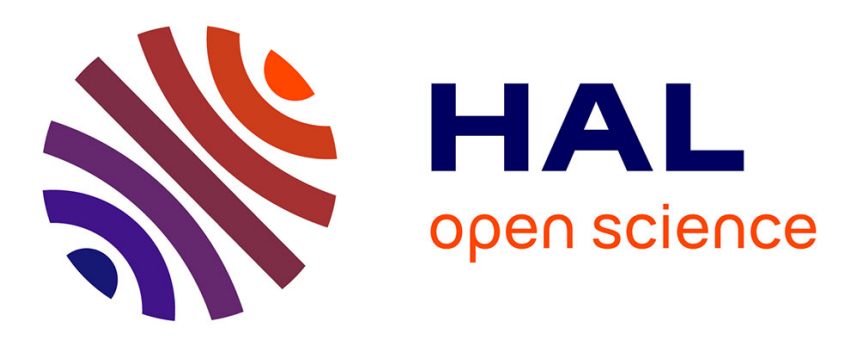

\title{
Controlling the polymerization of coniferyl alcohol with cyclodextrins
}

\author{
Lionel Tarrago, Camille Modolo, Mehdi Yemloul, Viviane Robert, Pierre \\ Rousselot-Pailley, Thierry Tron
}

\section{- To cite this version:}

Lionel Tarrago, Camille Modolo, Mehdi Yemloul, Viviane Robert, Pierre Rousselot-Pailley, et al.. Controlling the polymerization of coniferyl alcohol with cyclodextrins. New Journal of Chemistry, 2018, 42 (14), pp.11770-11775. 10.1039/C8NJ01039K . cea-01939414

\section{HAL Id: cea-01939414 https://hal-cea.archives-ouvertes.fr/cea-01939414}

Submitted on 3 Dec 2018

HAL is a multi-disciplinary open access archive for the deposit and dissemination of scientific research documents, whether they are published or not. The documents may come from teaching and research institutions in France or abroad, or from public or private research centers.
L'archive ouverte pluridisciplinaire HAL, est destinée au dépôt et à la diffusion de documents scientifiques de niveau recherche, publiés ou non, émanant des établissements d'enseignement et de recherche français ou étrangers, des laboratoires publics ou privés. 


\section{Controlling the polymerization of coniferyl alcohol with cyclodextrins}

\begin{tabular}{|r|l|}
\hline Journal: & New Journal of Chemistry \\
\hline Manuscript ID & NJ-ART-03-2018-001039.R1 \\
\hline Article Type: & Paper \\
\hline Date Submitted by the Author: & 15-May-2018 \\
\hline Complete List of Authors: & $\begin{array}{r}\text { Tarrago, Lionel; Aix Marseille Université, Centrale Marseille, CNRS, iSm2 } \\
\text { UMR 7313 13397 Marseille (France)., chemistry } \\
\text { Modolo, Camille; Aix Marseille Université, Centrale Marseille, CNRS, iSm2 } \\
\text { UMR 7313 13397 Marseille (France)., chemistry } \\
\text { Yemloul, Mehdi; Aix Marseille Université, Centrale Marseille, CNRS, iSm2 } \\
\text { UMR 7313 13397 Marseille (France)., chemistry } \\
\text { Robert, Viviane; Aix Marseille Université, Centrale Marseille, CNRS, iSm2 } \\
\text { UMR 7313 13397 Marseille (France)., chemistry } \\
\text { Rousselot-Pailley, Pierre; Aix Marseille Université, Centrale Marseille, } \\
\text { CNRS, iSm2 UMR 7313 13397 Marseille (France)., chemistry } \\
\text { tron, thierry; Aix Marseille Université, Centrale Marseille, CNRS, iSm2 UMR } \\
\text { 7313 13397 Marseille (France)., chemistry }\end{array}$ \\
\hline
\end{tabular}




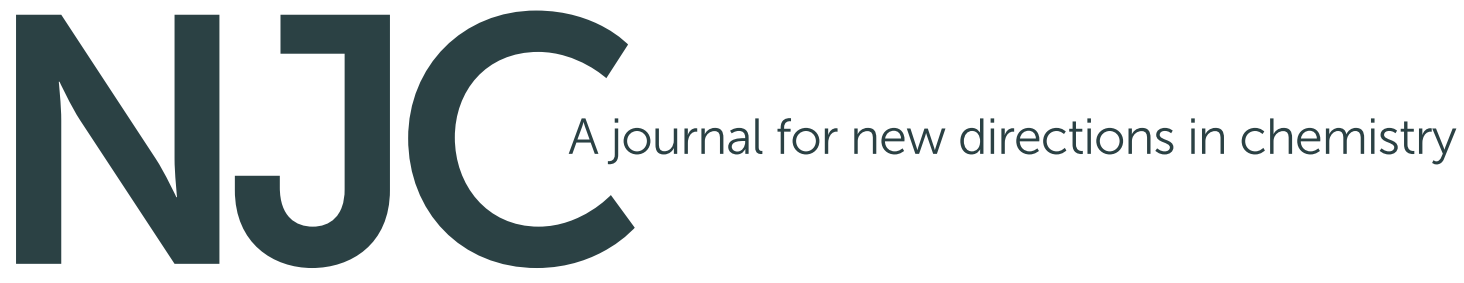

New Journal of Chemistry

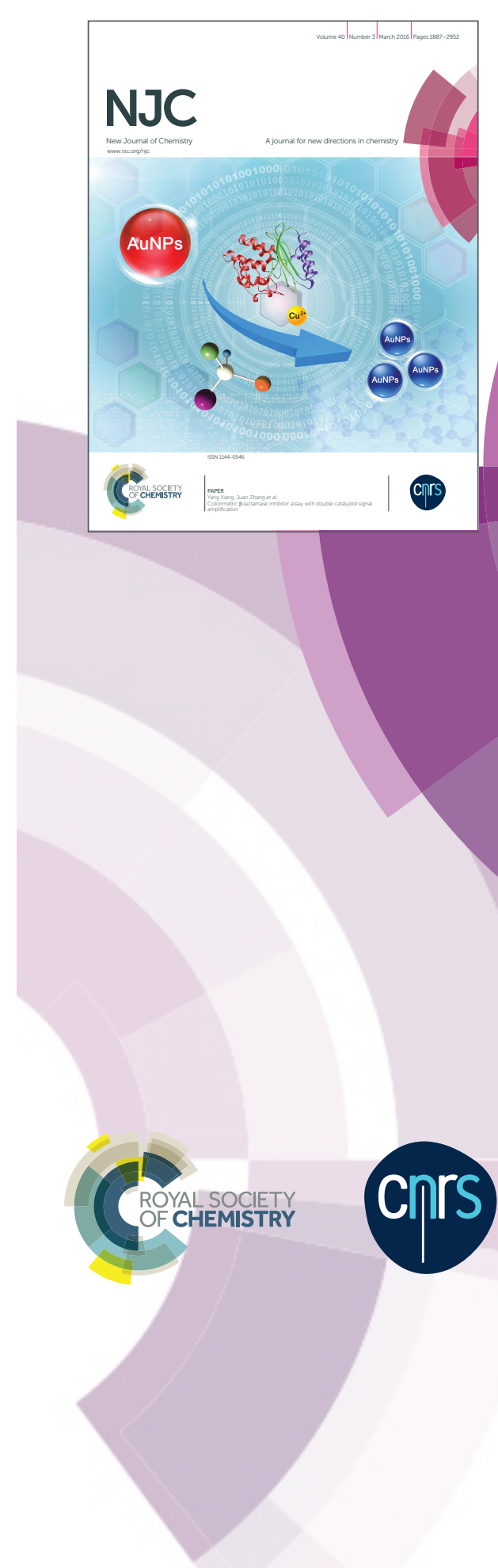

NJC is a general chemistry journal. We solicit innovative and cuttingedge reports of high quality and broad appeal that have the potential to open new directions in chemistry or other scientific disciplines. Both experimental and theoretical works are welcome.

\section{The following manuscript has been submitted for consideration as a PAPER}

Papers report a complete study that leads to new understanding or gives new insight into the subject under investigation. If preliminary results have been published in a communication, a subsequent full paper should include additional results that justify another publication.

The Editors and Editorial Board ask you as a reviewer to keep the criteria in mind when making your recommendation for publication in NJC. Routine or incremental work, however competently researched and reported, should not be recommended for publication in NJC as it does not meet our expectations with regard to novelty and impact.

Thank you for your help with the evaluation of this submission. The editors rely on experts such as yourself to improve the scientific quality of the journal. Please support your answers to the questions with appropriate comments to allow the editors to make the best decision and the authors to properly revise their manuscript.

If you recommend Major Revision or Reject and Resubmit then we would appreciate it if you would indicate your willingness to reevaluate the manuscript after revision.

We very much appreciate it if you can respect the deadline for filing your report. If you should need additional time to complete your report, please contact the editors at NJC@rsc.org.

\section{Professor Mir Wais Hosseini Editor-in-Chief of NJC}

We also invite you to consider NJC for one of your upcoming manuscripts. Submissions can be made on the Scholar One website: http://mc.manuscriptcentral.com/njc or follow the 'submit an article' link on the NJC homepage given below. 


\section{Journal Name}

\section{ARTICLE}

\section{Controlling the polymerization of coniferyl alcohol with cyclodextrins}

Received 00th January 20xx, Accepted 00th January 20xx

DOI: $10.1039 / x 0 x \times 00000 x$

www.rsc.org/
Lionel Tarrago*, Camille Modolo, Mehdi Yemloul, Viviane Robert, Pierre Rousselot-Pailley, Thierry Tron*

\section{Introduction}

Natural molecules such as sugars and amino acids are produced in cell as pure enantiomers by dedicated enzymes. One peculiar situation is however found in the synthesis of some plant metabolites (scheme 1) deriving from the monoelectronic oxidation of the lignol coniferyl alcohol (as the result from the activity of oxidases such as laccases) which leads initially to phenoxy radicals. ${ }^{1}$ In vitro a bimolecular radical coupling results in the transient accumulation of a mixture of ( \pm )-dehydrodiconiferyl alcohols (2), ( \pm )-pinoresinols (3), and ( \pm )-guaiacylglycerol 8-0-4-coniferyl alcohol ethers (4) prior a further polymerization. In plants however either the (+)- or (-)enantiomer of pinoresinol is preferentially formed. ${ }^{2}$ Regio- and enantioselectivity are provided by dirigent proteins (DP) such as FiDIR1 and AtDIR6, which have been shown to be respectively responsible for the formation of (+)-pinoresinol in Forsythia intermedia ${ }^{2 a}$ and of (-)-pinoresinol in Arabidopsis thaliana $^{2 \mathrm{~b}}$. These proteins, which might not possess a catalytic center per se, are proposed to act as a scaffold interacting with radicals of coniferyl alcohol to direct the bimolecular coupling through a yet undetermined host/guest mechanism. In a bioconversion, the combined use of these proteins and a laccase or a chemical oxidant such as ammonium persulfate allows the enantioselective enrichment of pinoresinol. ${ }^{4}$

Produced from the enzymatic degradation of starch the naturally occurring cyclic oligosaccharides cyclodextrins (CDs)

Aix Marseille Université, Centrale Marseille, CNRS, iSm2 UMR 731313397 Marseille (France).Emails : lioneltarrago@msn.com; thierry.tron@univ-amu.fr + Electronic Supplementary Information (ESI) available: Enzymes and chemicals; Synthesis of ( \pm )-guaiacylglycerol 8-0-4-coniferyl alcohol ethers (4); Coniferyl alcohol oxidation in the presence of $C D$; Fitting kinetics; Determination of the apparent association constant and complex structure by NMR; Evolution of lignans production as function of the initial coniferyl alcohol concentration. See DOI: $10.1039 / \mathrm{x} 0 \times x \times 0000 \mathrm{x}$

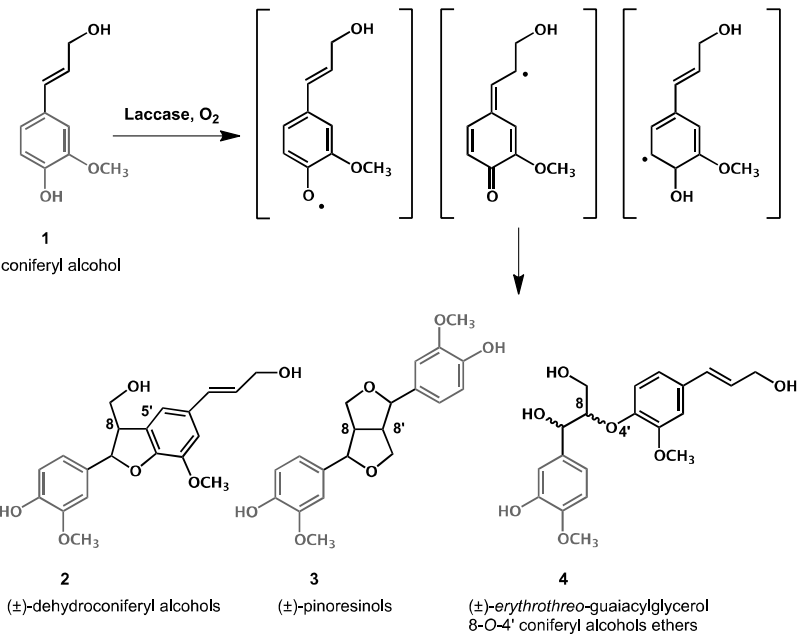

Scheme 1. Laccase catalysed oxidation of coniferyl alrohol

share with DPs the ability to host guest molecules. Most commons CDs are made of $6(\alpha C D), 7(\beta C D)$ or $8(\gamma C D) \alpha-D-$ glucopyranoside units linked by $\alpha-1,4$ bonds. ${ }^{3}$ They have the form of truncated cones in which the hydroxyl groups are exposed to the solvent, making the exterior of the cone hydrophilic whereas the interior, considerably less hydrophilic than the aqueous environment, is able to host hydrophobic molecules. While the height of the torus remains constant $(0.79 \mathrm{~nm})$, the cavity diameter varies from $0.47-0.53 \mathrm{~nm}$ for the $\alpha C D, 0.6-0.65 \mathrm{~nm}$ for the $\beta C D$ and $0.75-0.83 \mathrm{~nm}$ for the $\gamma C D$. The internal cavity volume of $\alpha, \beta$ and $\gamma C D$ directly influences the size of the guest a CD molecule can accommodate. $^{3}$ Because of these properties, CDs are used to enhance the solubility and bioavailability of numerous 
hydrophobic compounds such as drugs. ${ }^{3 \mathrm{~d}, \mathrm{e}}$ Moreover, CDs can selectively bind chiral molecules and are used to produce commercial HPLC columns for enantiomers separation. ${ }^{4}$ Notably, in enantioselective synthesis, CDs or their derivatized forms have been shown to increase the enantiopure production of $\beta$-amino alcohols ${ }^{5}$ and to facilitate the enantioselective $\mathrm{N}$-acylation of primary amines ${ }^{6}$. CDs have been also shown to significantly improve enantiomeric excess in enzyme-catalysed reactions, such as the peroxidase catalysed synthesis of binaphthyl derivatives from naphtols and the esterase catalysed synthesis of the $S$-enantiomer of the anti-inflammatory drug naproxen. ${ }^{7}$

In this work, we studied the influence of CDs with different cavity volumes on the laccase-driven oxidation of coniferyl alcohol in bimolecular systems in which the substrate is mixed with an excess of CDs. We are clearly showing that while the dimerization of coniferyl alcohol is unaffected by the presence of $C D$ s, the $\beta C D$ cavity is stabilizing the lignan products and prevent their further oxidation by the enzyme. Moreover, amongst the three lignans generated the combination of laccase with $\beta C D$ allows a selective enrichment of pinoresinol, a behaviour somehow reminiscent of lignan synthesis in the presence of plant dirigent proteins.

\section{Results and Discussion}

In vitro oxidation of coniferyl alcohol 1 (3-(4-Hydroxy-3methoxyphenyl)-2-propen-1-ol) $\left(2.5 \times 10^{-3} \mathrm{M}\right)$ by the fungal laccase LAC3 ${ }^{8}$ from Trametes sp. C30 $\left(5 \mathrm{U.L}^{-1}\right)$ generates lignans 2, $\mathbf{3}$ and $\mathbf{4}$ as initial products accumulating during the rapid phase of substrate consumption (see scheme 1). Influence of the CD cavity volume on the oxidation of 1 by LAC3 was evaluated in the presence of an excess $\left(12 \times 10^{-3} \mathrm{M}\right)$ of either $\alpha, \beta$ or $\gamma C D$. Both the consumption of 1 and the production of the dimeric lignans were followed as function of time by Reverse-Phase High Performance Liquid Chromatography (RPHPLC). Analysis of the chromatograms is presented Figure 1. In the absence of $\mathrm{CDs}$, the kinetic of consumption of $\mathbf{1}$ follows a decreasing exponential with a consumption of nearly $90 \%$ of the substrate during the first hour (Fig. 1, graph (1)). In our experimental conditions lignans $\mathbf{2}$ and $\mathbf{3}$ account for more than $80 \%$ of the dimers formed (Fig. 1, graphs (2) and (3)). ${ }^{\ddagger}$ The neosynthesized lignans containing phenolic moieties (i.e. a 2metoxyphenol), their concentration is rapidly high enough to compete with 1 as substrates for the LAC3 enzyme. Thus, after reaching a maximum (equilibrium between formation and disappearance) the concentration of lignans was significantly decreasing with initial velocities of $c a .0 .16 \times 10^{-3} \mathrm{~mol}^{-L^{-1}} \cdot \mathrm{h}^{-1}(2)$ and ca. $0.10 \times 10^{-3} \mathrm{~mol}^{-\mathrm{L}^{-1}} \cdot \mathrm{h}^{-1}$ (3) ((Fig. 1, graphs (2) and (3)). As the reaction proceeds through mono-electronic oxidations, these observations are consistent with a further oxidation of the dimeric lignans produced from coniferyl alcohol oxidation into polymers.

Evolution of the oxidation products was differentially influenced by the presence of $\alpha, \beta$ or $\gamma C D$ in the reaction mixture (Fig. 1). Addition of $\alpha C D$ to the reaction mixture had influence neither on the oxidation of $\mathbf{1}$ nor on that of the neosynthesized lignans. To the contrary, the presence of CDs with a larger cavity volume had a marked effect on the disappearance of the reaction products maintaining the concentration of the lignans $\mathbf{2}$ and $\mathbf{3}$ fairly stable around 80 to $85 \%$ of the maximum values for several hours without apparently affecting the oxidation rate of 1 (Fig. 1). Thus, addition of $\beta C D$ to the reaction mixture is stabilizing lignans, probably forming a $\beta-C D$ :lignan complex that is significantly slowing down lignans oxidation by the enzyme (vide infra).

Figure 1. Influence of $\mathrm{CDs}$ on the laccase catalysed oxidation of coniferyl alcohol. Coniferyl alcohol (1) $\left(2.5 \times 10^{-3} \mathrm{M}\right)$ was incubated with the laccase LAC3 $\left(5{\left.\mathrm{U} . \mathrm{L}^{-1}\right)}^{-1}\right.$ at $30^{\circ} \mathrm{C}$ in the absence (open square) or presence of an excess $\left(12 \times 10^{-3} \mathrm{M}\right)$ of either

(1)

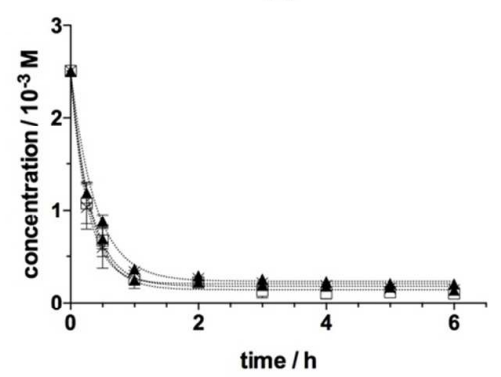

(2)

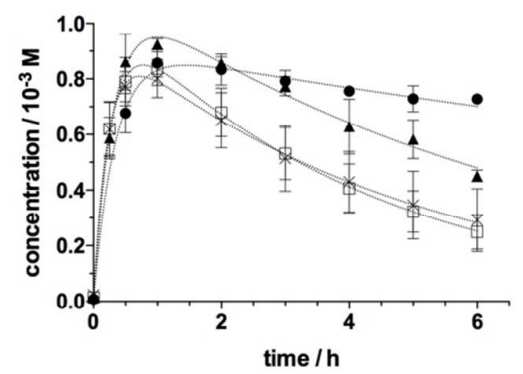

(3)

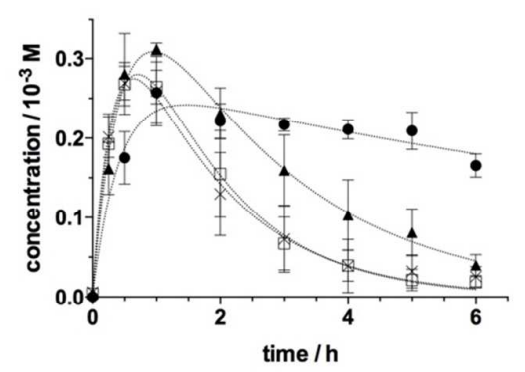

$\alpha C D$ (crosses), $\beta C D$ (black circles) or $\gamma C D$ (black triangles). Consumption of $\mathbf{1}$ and apparition of $\mathbf{2}$ and $\mathbf{3}$ were monitored by RPHPLC. Fits (dotted lines) were obtained either from a single decay (exponential) model (for the oxidation of 1 ) or are described in Supplementary Information.

In the presence of $\gamma C D$, the stabilization effect is clearly less pronounced as apparent initial rates of lignans oxidation were three times faster in the presence of $\gamma C D$ than in the presence of $\beta C D$ (ca. $0.09 \times 10^{-3} \mathrm{~mol} . \mathrm{L}^{-1} \cdot \mathrm{h}^{-1}$ vs. $0.03 \times 10^{-3} \mathrm{~mol} \cdot \mathrm{L}^{-1} \cdot \mathrm{h}^{-1}$ and
$0.06 \times 10^{-3} \mathrm{~mol} \cdot \mathrm{L}^{-1} \cdot \mathrm{h}^{-1}$ vs. $0.02 \times 10^{-3} \mathrm{~mol} \cdot \mathrm{L}^{-1} \cdot \mathrm{h}^{-1}$ for 2 and 3 respectively). Overall, in these experiments $\beta$ and $\gamma C D$ s have apparently no significant effect on the rate of oxidation of 1 
(2)

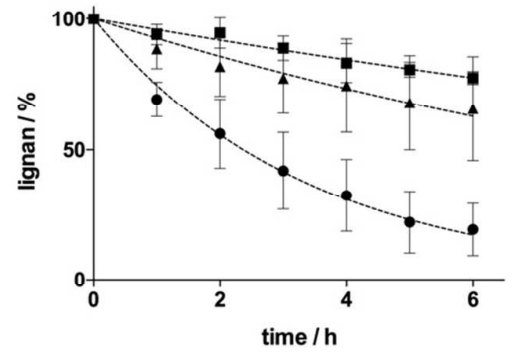

(3)

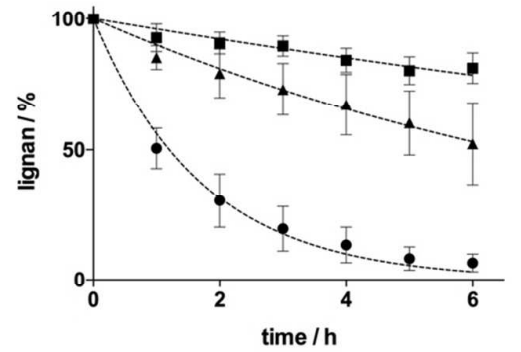

(4)

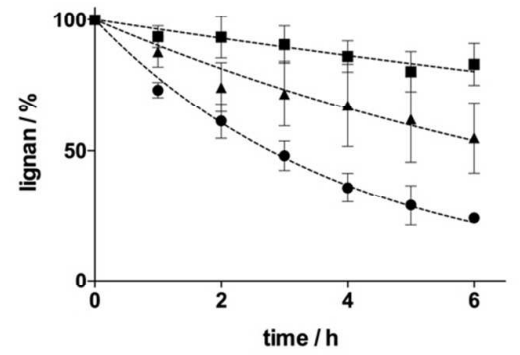

whereas they have a marked effect on the stabilization of lignans.

Figure 2. Influence of CDs on the laccase catalysed oxidation of lignans. Dehydroconiferyl alcohol (2), pinoresinol (3) or erythro guaiacyl glycerol $(4)\left(2.5 \times 10^{-3} \mathrm{M}\right)$ were each incubated with the laccase LAC3 $\left(5 \mathrm{U.L}^{-1}\right)$ at $30^{\circ} \mathrm{C}$ in the absence (black circles) or presence of an excess $\left(12 \times 10^{-3} \mathrm{M}\right)$ of either $\beta C D$ (black squares) or $\gamma C D$ (black triangles). Oxidations were monitored by RP-HPLC. Fits (dashed lines) were obtained using a single decay (exponential) model.

Both the apparent complexity of the kinetics due to an oxidation of the products concomitant to their generation and the absence of exploitable data on the fate of lignan $\mathbf{4}$ lead us to further study the oxidation of pure lignans (see Supplementary Information for details about the origin of lignans). In the absence of $C D, \mathbf{3}$ is oxidized by laccase at a significantly faster rate than 2 and 4 (i.e. $1.3 \times 10^{-3} \mathrm{~mol}^{-1} \mathrm{~L}^{-1} \cdot \mathrm{h}^{-1}$ vs $0.7 \times 10^{-3} \mathrm{~mol} . \mathrm{L}^{-1} \cdot \mathrm{h}^{-1}$ and $0.6 \times 10^{-3} \mathrm{~mol} \cdot \mathrm{L}^{-1} \cdot \mathrm{h}^{-1}$ respectively) the kinetics of oxidation of which were otherwise similar (Fig. 2 ). On the other hand, lignans oxidation rates are globally slower than the rate of oxidation of $\mathbf{1}$ (compare graph (1) from Fig. 1 and data (black circle) from Fig. 2). Amongst different factors, this might be mainly linked to differences in redox potentials between lignans and $\mathbf{1}$ (for example $E^{\circ} \mathbf{1}^{-} \mathbf{1}^{\circ}=0.48 \mathrm{~V}$ vs $\mathrm{SHE})^{9}$. Cleared of the step corresponding to the dimerization of $\mathbf{1}$, the effects of CDs on laccase-mediated oxidation of 2, 3 or 4 are simpler to analyse. Regardless of their specific oxidation rates, the oxidation of each lignan was similarly slowed down in the presence of $\beta\left(0.04 \mathrm{~h}^{-1}\right.$ for all lignans) or $\gamma C D\left(0.08\right.$ to $\left.0.1 \mathrm{~h}^{-1}\right)$ suggesting a similar mode of interaction of the three different lignans with each of the CDs. As observed previously for the oxidation products of $\mathbf{1}$ (Fig. 1), $\gamma C D$ was less effective than $\beta C D$ in protecting lignans from oxidation.

The ability of a $C D$ to form an inclusion complex with a guest molecule is function both of a steric factor (the relative size of the $C D$ cavity to the size of the guest) and of a thermodynamic factor (a driving force bringing the guest into the cavity). ${ }^{10}$ Altogether, the differential effects induced by $\alpha, \beta C D$ or $\gamma C D$ on coniferyl alcohol and lignans oxidation match well both the physico-chemical properties of guests and CDs structural differences (i.e. cavity volume and rigidity). Lignans 2 to $\mathbf{4}$ contain each at least one aromatic 2-metoxyphenol moiety inherited from their precursor the coniferyl alcohol molecule (1) (see scheme 1). The molecular volume of 2-metoxyphenol is estimated to be roughly $180 \AA^{3}$. Although an $\alpha$-CD:coniferyl alcohol inclusion complex has been postulated from $1 \mathrm{D}{ }^{1} \mathrm{H}$ NMR experiments ${ }^{11}$ it seems that the internal cavity of $\alpha C D$ $\left(174 \AA^{3}\right.$ ) might be eventually too small to stably accommodate neither the substrate nor the lignans. On the other hand, $y$ $\left(427 \AA^{3}\right)$ and $\beta\left(262 \AA^{3}\right)$ CDs are both likely capable to accommodate molecules of the volume of guaiacol and larger. As $\gamma C D$ is both larger and more flexible than $\beta C D, \gamma C D$ :lignan complexes are potentially less stable than $\beta C D$ :lignan complexes and that can account for observed kinetic differences. The absence of any "CD effect" on the oxidation kinetics of coniferyl alcohol (1) suggests that CDs may have a significantly less affinity for 1 than for lignans. Excepting $\alpha C D$ the cavity of which is probably too small (vide supra), $\gamma$ and $\beta C D$ cavities could be too large to stabilize 1 . Beyond the internal CD cavity volume, a simple examination of theoretical values describing the hydrophobic character and the water solubility of the ligand molecules point $\mathbf{1}$ as the least favourable ligand for forming an inclusion complex with CDs amongst the molecules we tested $(3>2>4>1) .{ }^{12}$

$\mathrm{CD}$ :guest complexes were studied by ${ }^{1} \mathrm{H}$ NMR experiments as their formation induce shifts of host and guest representative signals. Initially, the equilibrium between the constituents of a given complex was challenged in a titration of a low concentration of ligand (i.e. $500 \times 10^{-6} \mathrm{M}$ ) with increasing concentrations of CDs. Association constants $(K a)$ extracted from Scott Plots $\left([C D]_{0} / \Delta \delta_{\text {obs }}=f\left([C D]_{0}\right)\right.$, see Supplementary information Fig. SI2 for details) are presented in Table 1. Reflecting a dynamic exchange in $\mathrm{CD}$ :guest complexes $\mathrm{Ka}$ values are notoriously fairly low. ${ }^{10 a}$ As expected, values for $\gamma C D$ are lower than those calculated for $\beta C D$. Nevertheless, amongst complexes the apparent hierarchy $3: C D>2: C D>4: C D$ $>$ 1:CD matches that deduced from theoretical physicochemical properties of ligands (vide supra). Ka values for a potential 1:CD complex are extremely low and their significance questionable. Both the absence of substantial effect on the oxidation rate of $\mathbf{1}$ (see Fig. 1) and low $K a$ values strongly support that $\mathbf{1}$ is not forming stable complexes with CDs.

Table 1. Association constants $\left(\mathrm{M}^{-1}\right)$ measured for lignans/CD complexes. 


\begin{tabular}{ccc}
\hline Entry & $\beta C D$ & $\gamma C D$ \\
\hline $\mathbf{1}$ & 439 & 196 \\
$\mathbf{2}$ & 1065 & 269 \\
$\mathbf{3}$ & 1281 & 750 \\
$\mathbf{4}$ & 808 & 392 \\
\hline
\end{tabular}

In addition, plotting the extend of the shifts as function of the evolution of the molar ratio between the $C D(\beta$ or $\gamma C D)$ and the guest suggested a 1:1 stoichiometry for all the $C D$ :guest complexes studied (see Fig. SI3). Next, we used Rotating frame nuclear Overhauser Effect SpectroscopY (2D-ROESY) experiments to further characterize 1, 2, 3 and 4: $\beta C D$ inclusion complexes. Highlighting intra and inter-molecular spatial proximity (below $6 \AA$ ) the Nuclear Overhauser Effect is widely used for the characterization of host-guest intermolecular interactions. ${ }^{13}$ Globally, disregarding relaxation and molecular motions, in the phase sensitive 2D-ROESY experiments ${ }^{14}$ the integrated intensity of the cross-peaks is directly correlated with the inter-nuclear distance of the two observed protons. Beyond the observation of ${ }^{1} \mathrm{H}$ chemical shift displacements of host and/or guest molecules as often found in descriptions of ligand:CD complexes, this approach allows a more accurate description of inclusion complexes classifying interatomic distances from each $\beta C D$ proton. For each complex, we studied the cross peaks involving $\mathrm{H}^{\prime} 3$ and $\mathrm{H}^{\prime} 5$ protons from the inside of the CDs cavity and the $\mathrm{H}^{\prime} 6$ proton located out at the narrow rim (crown). 2D-ROESY spectra in which the intermolecular cross-peaks are highlighted are

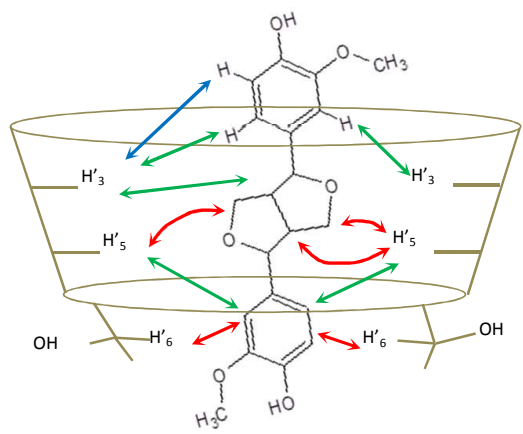

presented in supplementary information (Fig. SI4 and SI5).

Figure 3. Schematic view of a potential $\mathrm{CD} /( \pm)$-pinoresinol inclusion complex as deduced from 2D-ROESY data. Double arrows indicate spatial dipolar interactions classified from each CD proton: close (red), intermediate (green), far (blue).

These NMR data are consistent with a potential insertion of lignans $\mathbf{2 ,} \mathbf{3}$ or $\mathbf{4}$ into the $\beta C D$ cavity and their stabilization at the narrow rim. A scheme of a potential inclusion complex reflecting correlations observed between protons $\mathrm{H} 2, \mathrm{H} 5, \mathrm{H} 6$ of 3 and protons $H^{\prime} 3, H^{\prime} 5, H^{\prime} 6$ of $\beta C D$ is proposed in Figure 3. However, as CD may also form non-inclusion complexes with guest molecules, ${ }^{3}$ a stabilization of lignans at the narrow rim but outside the cavity cannot be formally ruled out. Whatever their structure (i.e. inclusion or non-inclusion), $\beta C D$ :guest complexes stabilize lignans thereby offering them a protection against oxidation.

Considering the above results, only $\beta C D$ was further investigated. Proportions of lignans 2, $\mathbf{3}$ and $\mathbf{4}$ derived from the oxidation of $\mathbf{1}$ were found insensitive to a variation of the $\beta-C D$ concentration (0-13 $10^{-3} \mathrm{M}$ range). Whereas in several cases of catalysed reactions the presence of $\beta C D$ has been shown to influence the selectivity ${ }^{5-7,15-19}$, there is here no selectivity in the oxidation of $\mathbf{1}$ (as assessed by separation of the lignan products on a chiral column) simply because $\mathbf{1}$ is not

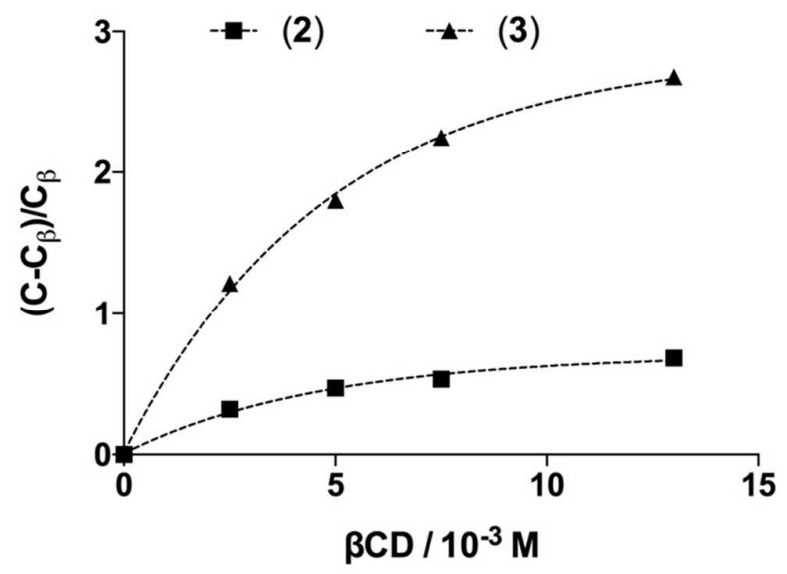

(or too weakly) interacting with the CD. Besides, amounts of lignans remaining non-oxidized in the reaction mixture were found to follow a saturation profile as the concentration of $\beta C D$ increased (Fig. 4).

Figure 4. Influence of varying the concentration of $\beta C D$ on final concentrations of lignans. Lignans $\left(2.5 \times 10^{-3} \mathrm{M}\right)$ were incubated with the laccase LAC3 $\left(5 \mathrm{U}^{\mathrm{L}} \mathrm{L}^{-1}\right)$ at $30^{\circ} \mathrm{C}$ in the presence of variable concentrations $\left(0-13 \times 10^{-6} \mathrm{M}\right)$ of $\beta C D$ for 6 hours. $C=$ lignan concentration in the absence of $\beta C D ; C_{\beta}=$ lignan concentration in the presence of $\beta C D$. Fits (dotted lines) were obtained using a one-phase association (exponential) model.

Comparatively, the amplitude of the variation in dimer concentrations in the presence of $\beta C D$ versus in the absence of $\beta C D$ is higher for dimer $\mathbf{3}$ than for dimer $\mathbf{2}$ (note that the concentration of $\mathbf{4}$ was too low be properly analysed). Since oxidation rates of lignans $\mathbf{2}$ and $\mathbf{3}$ obtained in the presence of $\beta C D$ are quite similar (see Fig. 2), this behaviour is totally attributable to differences in oxidation rates of the lignans by the enzyme alone. On the other hand, the protective effect of $\beta C D$ on lignan oxidation decreased as the initial concentration of 1 increased (Fig. SI6). This is both related to the rate of lignan synthesis and to the formation of lignan:CD complexes that is limited by the concentration of $\beta C D\left(12-13 \times 10^{-3} \mathrm{M}\right)$. With a LAC3 apparent Michaelis constant ( $\left.K_{\text {Mapp }}\right)$ value estimated around $10 \times 10^{-3} \mathrm{M}$ for $\mathbf{1}$, the rate of lignans formation is likely not maximal at low concentrations of $\mathbf{1}$ (e. g. 
$\left.2.5 \times 10^{-3} \mathrm{M}\right)$. All lignans produced are probably forming a complex with $\beta C D$ molecules which protects them from a further oxidation by LAC3. As the concentration of $\mathbf{1}$ increases, lignans accumulate and there is a competition between lignans: $\beta C D$ complexes formation and oxidation of lignans by LAC3.

CDs are known to interact with the surface of macromolecules, a property often used to stabilize these objects. ${ }^{20}$ Beyond a sequestration of the substrate ${ }^{21}$ that is apparently here not influencing the fate of $\mathbf{1}$ (vide supra), a direct laccase:CD interaction was challenged. Whether or not $B C D$ interferes with the oxidation of $\mathbf{1}$ by LAC3 (pseudo competition) was tested recording enzyme kinetics in the presence of increasing concentrations of $\beta C D$. $\beta C D$ had no influence on initial rates of consumption of 1 . Neither it has an influence on initial rates of production of dimers as dimerization occurs through a radicalradical coupling independent of the presence of the enzyme. Therefore, in the oxidation of $\mathbf{1}, \beta C D$ is not a modulator of the laccase activity neither through the formation of a complex with 1 or through a direct CD:enzyme interaction. This leaves that the observed stabilisation of the dimers is entirely due to their interaction with the $\beta C D$.

\section{Experimental}

All chemicals were purchased from Sigma-Aldrich and used as received except for $\beta C D$ which was recrystallized twice in $60 \%$ ethanol. The laccase LAC3 (from Trametes sp C30) ${ }^{8 a}$ was produced in Aspergillus niger and purified as previously described ${ }^{8 \mathrm{~b}}$. Oxidation of coniferyl alcohol was performed with laccase at $30^{\circ} \mathrm{C}$ in BrittonRobinson buffer adjusted at $\mathrm{pH} 5.0$ and oxidation products were separated by reverse phase HPLC. All NMR experiments were performed at $298 \mathrm{~K}$ in $\mathrm{D}_{2} \mathrm{O}$ on a Bruker Avance III $600 \mathrm{MHz}$ spectrometer, equipped with a $5 \mathrm{~mm}$ triple resonance high resolution probe. All NMR datasets were processed in TOPSPIN 3.2 version (Bruker BioSpin, Germany).

\section{Conclusions}

The use of cyclodextrins in the laccase catalysed oxidation of coniferyl alcohol allows a control of the polymerisation by a stabilisation of the dimers resulting from radical coupling. Stabilisation goes through complexes depending on the size of the $C D$ cavity and is maximum for $\beta C D$. Whereas a $C D$ :coniferyl alcohol inclusion complex is not forming in the catalytic conditions used, all three dimeric lignans are protected from further oxidation by the enzyme through a complexation by CDs. As the oxidation rate of the unprotected $( \pm)$ pinoresinol is faster than that of the other lignans, the formation of a complex with $\beta C D$ induces an apparent bias in the relative proportions of dimers. So, amongst the three lignans generated the laccase- $\beta C D$ system allows a selective enrichment of pinoresinol, a behaviour somehow resembling that of plant dirigent proteins. ${ }^{2}$ Overall, results obtained from this study point a selective interaction of CDs with lignans and open the possibility to use CDs to control the polymerization process of lignans or related phenolic molecules for the synthesis of molecules of interest.

\section{Conflicts of interest}

There are no conflicts to declare.

\section{Acknowledgements}

This study was supported by funds from the CNRS and Aix Marseille Université and from a grant from the Agence Nationale de la Recherche (ANR-09-BLANC-0176). CM is a recipient of a fellowship from the Fondation Pierre Pottier. We thank Elise Courvoisier-Dezord from the Plateforme AVB (AMU): Analyse et Valorisation de la Biodiversité and Yolande Charmasson for help in the production of the recombinant enzymes. We also thank Frédéric Turpin and El Mustapha Belgsir (Biocydex Ltd) as well as Ariane J. Simaan for helpful discussions.

\section{Notes and references}

$¥$ In the conditions chosen for a maximum separation of $\mathbf{2}$ and $\mathbf{3}$, peaks of $\mathbf{1}$ (decreasing) and $\mathbf{4}$ (increasing) were coincidental, both preventing a precise follow up of the kinetics of the appearance of the minor product $\mathbf{4}$ and introducing a bias in the evaluation of the concentration of 1 . Although the effect is minor for the interpretation of the kinetics for $\mathbf{2}$ and $\mathbf{3}$ this has to be stated here.

1 C. Paniagua, A. Bilkova, P. Jackson, S. Dabravolski, W. Riber, V. Didi, J. Houser, N. Gigli-Bisceglia, M. Wimmerova, E. Budinska, T. Hamann, J. Hejatko, J. Exp. Botany, 2017, 68, 3287.

2 a) L. B. Davin, H. B. Wang, A. L. Crowell, D. L. Bedgar, D. M. Martin, S. Sarkanen, N. G. Lewis, Science 1997, 275 362; b) B. Pickel, M. A. Constantin, J. Pfannstiel, J. Conrad, U. Beifuss, A. Schaller, Angew. Chem. Int. Edit., 2010, 49, 202.

3 a) H. Dodziuk, in Cyclodextrins and Their Complexes, Wiley-VCH Verlag GmbH \& Co. KGaA, 2006, pp. 1-30; b) S. Divakar, M. S. Narayan, A. K. Shaw, Indian J. Chem. B 1993, 32, 387; c) J. Szejtli, Chem. Rev. 1998, 98, 1743-1753; d) M. E. Brewster, T. Loftsson, Adv. Drug. Deliver. Rev., 2007, 59, 645; e) T. Loftsson, D. Hreinsdottir, M. Masson, Int. J. Pharm., 2005, 302, 18.

4 a) D. W. Armstrong, M. Hilton, L. Coffin, Lc Gc-Mag. Sep. Sci., 1991, 9, 646; b) A. Motoyama, A. Suzuki, O. Shirota, R. Namba, J. Pharmaceut. Biomed., 2002, 28, 97.

5 L. R. Reddy, N. Bhanumathi, K. R. Rao, Chem. Comm. 2000, 2321.

6 H. Asahara, T. Kida, T. Iwamoto, T. Hinoue, M. Akashi, Tetrahedron, 2014, 70, 197.

7 F. Trotta, L. Costa, G. Cravotto, J. Incl. Phenom. Macro. 2002, 44, 341.

8 a) A. Klonowska, C. Gaudin, M. Asso, A. Fournel, M. Reglier, T. Tron, Enzyme Microb. Tech., 2005, 36, 34; b) Y. Mekmouche, S. Zhou, A. M. Cusano, E. Record, A. Lomascolo, V. Robert, A. J. Simaan, P. RousselotPailley, S. Ullah, F. Chaspoul, T. Tron, J. Biosci. Bioeng., 2014, 117, 25. 
9 P. Hapiot, J. Pinson, P. Neta, C. Francesch, F. Mhamdi, C. Rolando, S. Schneider, Phytochem., 1994, 36, 1013.

10 a) K. A. Connors, Chem Rev 1997, 97, 1325; b) E. M. M. Del Valle, Process Biochem., 2004, 39, 1033.

11 R. Nakamura, Y. Matsushita, K. Umemoto, A. Usuki, K. Fukushima, Biomacromolecules, 2006, 7, 1929.

12 a) I. V. Tetko, J. Gasteiger, R. Todeschini, A. Mauri, D. Livingstone, P. Ertl, V. Palyulin, E. Radchenko, N. S. Zefirov, A. S. Makarenko, V. Y. Tanchuk, V. V. Prokopenko, J. Comput. Aid. Mol. Des., 2005, 19, 453; b) VCCLAB, Virtual Computational Chemistry Laboratory, http://www.vcclab.org, 2005.

13 H. J. Schneider, F. Hacket, V. Rudiger, H. Ikeda, Chem. Rev., 1998, 98, 1755.

14 a) A. Bax, D. G. Davis, J. Magn. Reson., 1985, 63, 207; b) T. L. Hwang, A. J. Shaka, J. Am. Chem. Soc., 1992, 114, 3157.

15 a) R. Breslow, P. Campbell, J. Am. Chem. Soc., 1969, 91, 3085; b) M. Komiyama, J. Chem. Soc. Chem. Comm. $1988,651$.

16 A. Ghanem, Org. Biomol. Chem., 2003, 1, 1282.

17 M. Singh, R. Sharma, U. C. Banerjee, Biotechnol. Adv., 2002, 20, 341.

18 R. Villalonga, R. Cao, A. Fragoso, Chem. Rev., 2007, 107, 3088.

19 R. Ravichandran, S. Divakar, J. Inclus. Phenom. Mol., 1993, 16, 201.

20 a) K. Griebenow, Y. D. Laureano, A. M. Santos, I. M. Clemente, L. Rodríguez, M. W. Vidal, G. Barletta, J. Am. Chem. Soc., 1999, 121, 8157; b) S. Schmitz, H. Ritter, Angew. Chem. Int. Ed., 2005, 44, 5658; c) T. Serno, R. Geidobler, G. Winter, Adv. Drug. Deliver. Rev., 2011, 63, 1086.

21 a) P. L. Irwin, P. E. Pfeffer, L. W. Doner, G. M. Sapers, J. D. Brewster, G. Nagahashi, K. B. Hicks, Carbohyd. Res., 1994, 256, 13; b) M. M. Sojo, E. Nunez-Delicado, F. Garcia-Carmona, A. Sanchez-Ferrer, J. Agr. Food. Chem. 1999, 47, 518; c) E. Nunez-Delicado, M. M. Sojo, A. Sanchez-Ferrer, F. Garcia-Carmona, Arch. Biochem. Biophys. 1999, 367, 274; d) E. Orenes-Pinero, F. GarciaCarmona, A. Sanchez-Ferrer, J. Mol. Catal. B-Enzym., 2007, 47, 143. 


\title{
Controlling the polymerization of coniferyl alcohol with cyclodextrins.
}

\author{
Lionel Tarrago*, Camille Modolo, Mehdi Yemloul, Viviane Robert, Pierre Rousselot-Pailley, Thierry Tron* \\ Aix Marseille Université, CNRS, iSm2 UMR 7313, 13397, Marseille, France \\ * Corresponding authors: Lionel Tarrago, Thierry Tron \\ E-mail address: lioneltarrago@msn.com; thierry.tron@univ-amu.fr
}

\section{Supplementary Information}

\section{Enzymes and chemicals}

The laccase LAC3 (from Trametes sp C30) was produced in Aspergillus niger and purified as described previously. ${ }^{1}$ Protein concentration was estimated by UV-visible spectroscopy using an $\varepsilon_{600 \mathrm{~nm}}=5 \times 10^{3} \mathrm{M}^{-1} \cdot \mathrm{cm}^{-1}$ for the T1 copper. Laccase activity of the purified protein solution was assayed using 2,2'-azino-bis(3-ethylbenzthiazoline-6-sulphonic acid) (ABTS). One unit (U) of laccase oxidizes one micromole of ABTS per minute.

Alpha-cyclodextrin $(\alpha C D)$, beta-cyclodextrin $(\beta C D)$ and gamma-cyclodextrin $(\gamma C D)$ were obtained from Aldrich or $\mathrm{TCl}$ Europe. Beta-cyclodextrin $(\beta C D)$ was recrystallized twice in $60 \%$ ethanol. Dehydrodiconiferyl alcohols (2) and ( \pm )-pinoresinols (3) were obtained from the bioconversion of coniferyl alcohol (1) (purchased from Sigma France) catalysed by the enzyme LAC3, purified by preparative chromatography (silica) and characterized by ${ }^{1} \mathrm{H}$ NMR and mass spectrometry. All other chemicals were purchased from Sigma France.

\section{Synthesis of ( \pm )-guaiacylglycerol 8-0-4-coniferyl alcohol ethers (4)}

4 was obtained by oxidation of 1 in the presence of silver oxide $\left(\mathrm{Ag}_{2} \mathrm{O}\right)$ following a protocol described Kishimoto et al., $2015 .^{2}$ The product of interest was purified by preparative chromatography (silica) and characterized by ${ }^{1} \mathrm{H}$ NMR and mass spectrometry.

\section{Coniferyl alcohol oxidation in the presence of $C D$}

Oxidation of coniferyl alcohol was performed at $30^{\circ} \mathrm{C}$ in Britton-Robinson buffer adjusted at pH 5.0 and oxidation products were detected by reverse phase HPLC. A typical reaction mixture $(1 \mathrm{~mL})$ contained LAC3 $(5 \mathrm{U} / \mathrm{L})$ and coniferyl alcohol $\left(2.510^{-3} \mathrm{M}\right)$ in the absence or presence of CD (up to 12 $10^{-3} \mathrm{M}$ ). The reaction proceeded for 8-hours and was initiated by the addition of the enzyme. For each time-point, the reaction was stopped by mixing $100-\mu \mathrm{L}$ aliquot to $100 \mu \mathrm{L}$ acetonitrile containing $2.85 \mathrm{mM}$ benzophenone. $30 \mu \mathrm{L}$ was injected on C18 column (EC150/4 Nucleosil ${ }^{\circledR} 100-5-18$ MachereyNage $^{\mathrm{TM}}{ }^{\text {) }}$ and analyzed by HPLC (Waters ${ }^{\mathrm{TM}}$ Alliance $^{\circledR}$ 2690/2690D Separations Module) with the following gradient: solvent $A$ water containing $3 \%$ acetic acid, solvent $B$ acetonitrile; $t=0 \mathrm{~min} 90 \% A$ $10 \% \mathrm{~B}, \mathrm{t}=5 \mathrm{~min} 90 \% \mathrm{~A} 10 \% \mathrm{~B}, \mathrm{t}=25 \mathrm{~min} 50 \% \mathrm{~A} 50 \% \mathrm{~B}, \mathrm{t}=27 \mathrm{~min} 50 \%$ A 50\% B, $\mathrm{t}=28 \mathrm{~min} 90 \% \mathrm{~A} 10 \% \mathrm{~B}$, $\mathrm{t}=30 \mathrm{~min} 90 \% \mathrm{~A} 10 \% \mathrm{~B}$. Coniferyl alcohol, dehydrodiconiferyl alcohol, pinoresinol and benzophenone were eluted at $4.0 \mathrm{~min}, 6.6 \mathrm{~min}, 8.2 \mathrm{~min}$ and $16.6 \mathrm{~min}$, respectively. Quantity was normalized using benzophenone as internal reference.

Apparent $K_{M}$ and $k_{c a t}$ values were obtained from the initial rate $(v)$, enzyme concentration (E) and substrate concentration (S) according to the equation $v=k_{\text {cat }} \mathrm{ES} /\left(K_{M}+\mathrm{S}\right)$. Inhibition kinetics data were obtained using appropriate equations. All data were determined using non-linear regression fitting using Prism software, Graphpad, San Diego, (CA). Because laccase catalysis involves two 
substrates and the $\left[\mathrm{O}_{2}\right]$ was invariant and assumed to be saturating in this study, the measured $K_{M}$ for the various substrates used should be considered apparent. Because of the assumption that $100 \%$ of the laccase participated in the catalysis as active enzyme, the measured $k_{\text {cat }}$ should also be considered apparent.

\section{Fitting kinetics}

The oxidation of coniferyl alcohol (1) by the enzyme laccase is a mono-electronic process leading to the transient formation of a radical species $\left(1^{\circ}\right)$ (eq. 1 ). Radical molecules recombine to give dimers 2, 3 and $\mathbf{4}$ according to eq. 2. Dimers are themselves subsequently oxidized by the enzyme (eq. 2, 4, 5) in a reaction similar to the oxidation of 1.

$$
\begin{aligned}
& 1 \frac{k_{1}}{-\mathrm{H}^{+}-\mathrm{e}^{-}} \mathbf{1}^{\cdot} \\
& n \mathbf{1}^{\bullet} \stackrel{k_{d i m}}{\longrightarrow} m \mathbf{2}+k \mathbf{3}+l \mathbf{4} \\
& 2 \frac{k_{2}}{-\mathrm{H}^{+}-\mathrm{e}^{-}} \mathbf{2}^{\cdot} \\
& \left.3 \underset{-\mathrm{H}^{+}-\mathrm{e}^{-}}{\stackrel{k_{3}}{-}} \quad \text { (eq. } 4\right) \\
& 4 \underset{-\mathrm{H}^{+}-\mathrm{e}^{-}}{\stackrel{k_{4}}{-}} 4^{\cdot} \quad \text { (eq. 5) }
\end{aligned}
$$

Kinetic data presented in Figure 1 from the main article were simulated using the stochastic kinetics simulator Kinetiscope (freeware) ${ }^{3}$. In the simulation, we introduced:

- the initial concentration of coniferyl alcohol [1] $=2.510^{-3} \mathrm{M}$

- rate constants from (eq. $1,3,4,5$ ) initially derived from experimental data presented in Fig. 1 and Fig. 2 from the main article: $k_{1}=3.3 \mathrm{~h}^{-1} ; k_{2}=0.3 \mathrm{~h}^{-1} ; k_{3}=0.5 \mathrm{~h}^{-1} ; k_{4}=0.25 \mathrm{~h}^{-1}$

- a bi-molecular constant $k_{\text {dim }}$ from (eq. 2) arbitrary set to a value of $>k_{1}, k_{2}, k_{3}, k_{4}$ (i.e.10 $0^{6} \mathrm{M}^{-1}$. $\left.\mathrm{h}^{-1}\right)$. With this approximation we recognize the recombination of radicals as a process considerably faster than oxidation steps and we do not distinguish the formation of each dimer 2, $\mathbf{3}$ and $\mathbf{4}$ (eq. 2).

The model obtained (Fig. SI1) is compatible with experimental data (Fig. 1 main text).

\section{simulation}

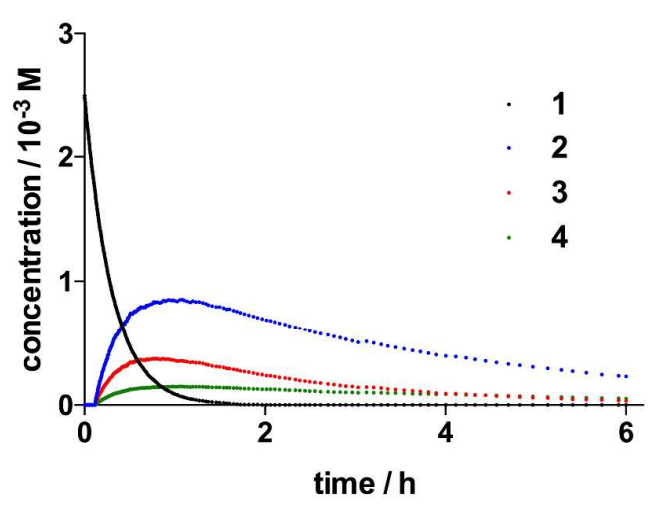

Figure SI1. Simulation of the formation of lignans from the oxidation of coniferyl alcool. Stochastic calculations performed with the freeware Kineticsope. Initial parameters: $[1]=2.510^{-3} \mathrm{M}, k_{1}=3.3 \mathrm{~h}^{-1} ; k_{2}=0.3$ $\mathrm{h}^{-1} ; k_{3}=0.5 \mathrm{~h}^{-1} ; k_{4}=0.25 \mathrm{~h}^{-1}$. 
Eventually, kinetics of the two successive oxidations leading to the formation and to the disappearance of each dimer (see Fig. 1 panels 2 and 3 main text) can be fitted using the simple model:

$$
\mathrm{A} \stackrel{k_{1}}{\longrightarrow} \mathrm{B} \stackrel{k_{2}}{\longrightarrow} \mathrm{C}
$$

treated as a succession of order 1 kinetics in which the dimerization step is not influencing the rate (i.e. $k_{\text {dim }}>k_{1}, k_{2}$ ).

$$
\mathrm{Y}=\left(\left(\mathrm{a} * k_{1}\right) /\left(k_{2}-k_{1}\right)\right) *\left(\exp \left(-k_{1} * \mathrm{X}\right)-\exp \left(-k_{2} * \mathrm{X}\right)\right)
$$

with $k_{1}=$ rate constant for the oxidation of the alcohol and $k_{2}=$ rate constant for the oxidation of the dimer.

\section{Determination of the apparent association constant and complex structure by NMR}

All experiments were performed at $298 \mathrm{~K}$ in $\mathrm{D}_{2} \mathrm{O}$ on a Bruker Advance III $600 \mathrm{MHz}$ spectrometer, equipped with a $5 \mathrm{~mm}$ triple resonance high resolution probe. All NMR datasets were processed in TOPSPIN 3.2 version (Bruker BioSpin, Germany). Proton NMR spectra were acquired with a spectral width of $6000 \mathrm{~Hz}$ and relaxation delay of 2s during which a water pre-saturation was applied.

$K a$ values were extracted from Scott plots $\left([C D]_{t} /\right.$ ? ? $\left.\left.\left._{\mathrm{obs}}=\left([C D]_{\mathrm{t}} / \text { [? }\right]_{\mathrm{c}}\right)+(1 / \mathrm{Ka} \text { ? }]_{\mathrm{c}}\right)\right){ }^{4}$

$\delta I=$ chemical shift of a proton from the ligand or from the free CD.

$\delta c=$ chemical shift of the same proton in the ligand:CD complex.

$\Delta$ obs $=\delta \mathrm{I}-\delta \mathrm{c}$

Plots for $\beta C D$ complexes are given in Figure SI2.

(1)

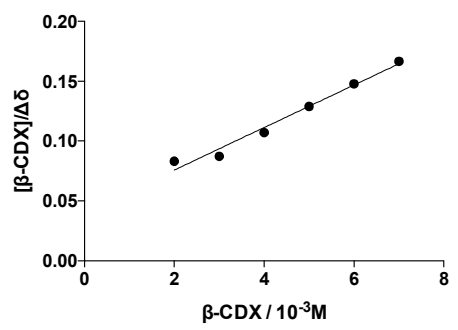

(3)

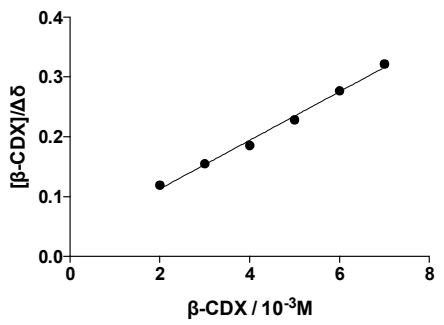

(2)

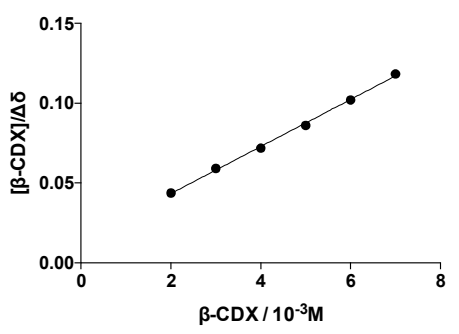

(4)

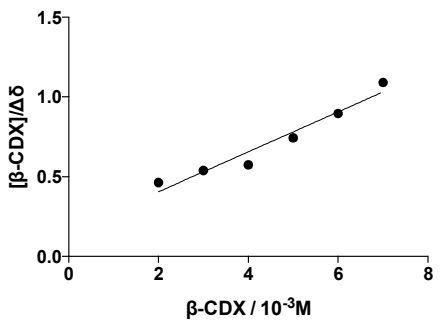

Figure S12. Representation of the ligand: $\beta C D$ interaction (Scott plots). [Ligand] $=0.510^{-3} \mathrm{M},[\beta C D]=2-710^{-3} \mathrm{M}$.

The stoichiometry for all the CD:guest complexes was studied plotting the extend of the shifts as function of the evolution of the molar ratio between the $C D$ ( $\beta$ or $\gamma C D$ ) and the ligand (Job Plots). Plots for $\beta C D$ complexes are given in Figure SI3. 
For complex structure analysis, 2D phase-sensitive ROESY were acquired by pulse field gradientselected methods, with 32 scans and 2048-time domain in F2, and 384 experiments in F1 by using the TPPI method and a mixing time (spin-lock) of $200 \mathrm{~ms}$ at a field of $6 \mathrm{kHz}$.

(1)

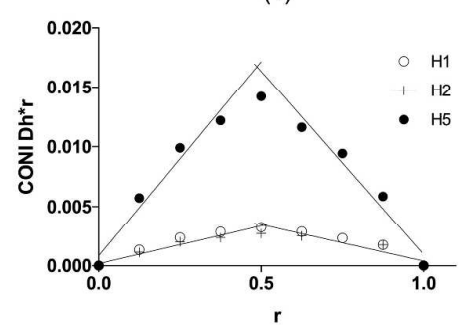

(3)

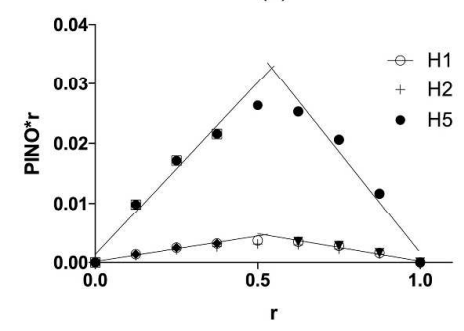

(2)

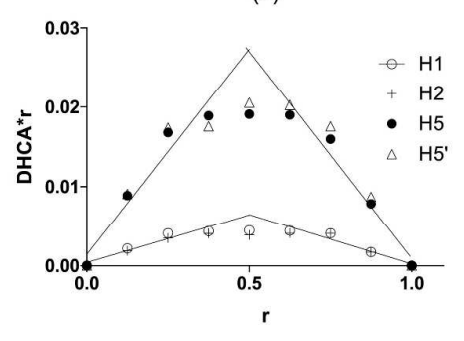

(4)

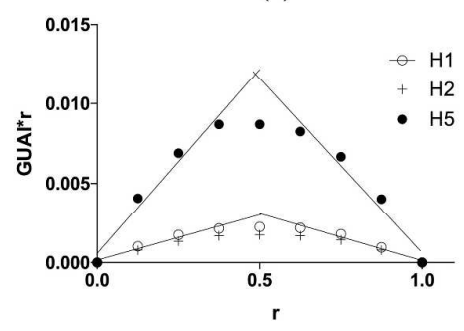

Figure SI3. Representation of the ligand: $\beta C D$ interaction (Job plots). [Ligand] $=0-810^{-3} \mathrm{M},[\beta C D]=8-010^{-3} \mathrm{M}$. Chemical shifts from $\beta C D$ protons $\mathrm{H} 1, \mathrm{H} 2$ and $\mathrm{H} 5$.

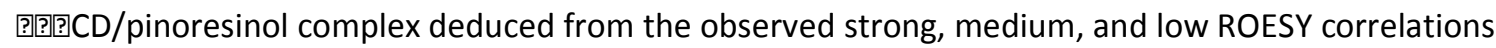
effects between protons $\mathrm{H}_{2}, \mathrm{H}_{5}, \mathrm{H}_{6}$ of ( \pm )-pinoresinol and protons $\mathrm{H}_{3}{ }_{3}, \mathrm{H}^{\prime}{ }_{5}, \mathrm{H}_{6}{ }_{6}$ of ?] $\mathrm{CD}$ is presented in the main text (Fig. 3). The proposed model is consolidated by strong interactions between protons $\mathrm{H}_{8}$ and $\mathrm{H}_{9}$ of ( \pm )-pinoresinol with protons $\mathrm{H}_{5}$ of 의? $\mathrm{CD}$ (red double arrows).

It should be pointed out that only unambiguous correlations were considered. Those with overlapping patterns potentially involving intramolecular interactions were discarded as for example in the coniferyl alcohol 2D-ROESY map (see red rectangle in panel B of Fig. SI.4).

A

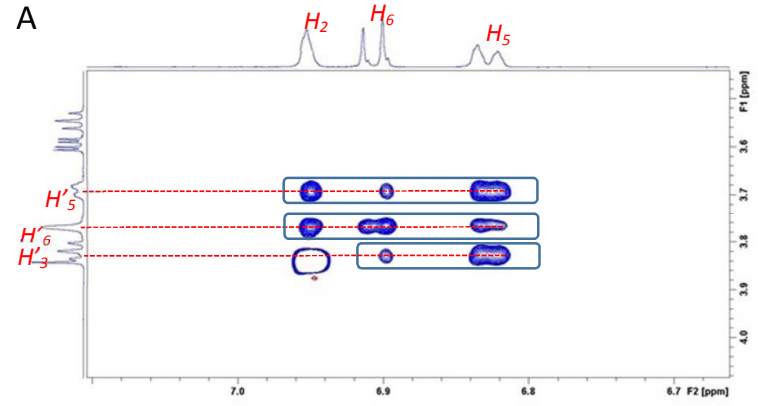

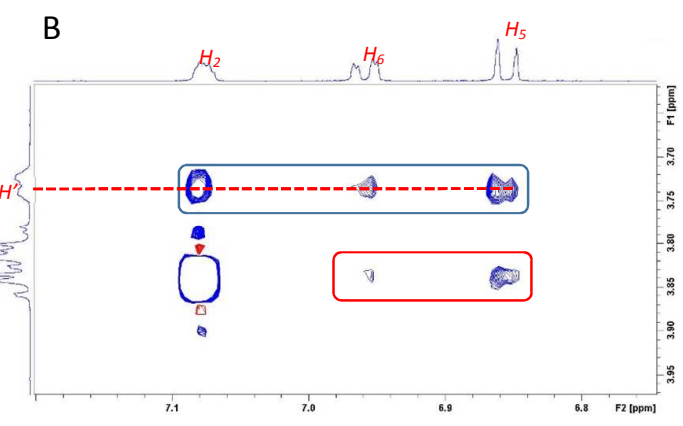

Figure S14. Fragments of ROESY spectra showing the intermolecular interactions between protons from ligands and proton from $\beta C D$. Panel $A$, ligand $=( \pm)$-pinoresinol; panel $B$, ligand $=$ coniferyl alcohol.

Interaction of dehydro di-coniferyl alcohol with a-CD led to splitting of some peaks in the 2D-ROESY spectrum indicating the presence of diastereoselective complexes that exhibit different cross peaks. The model proposed in Figure $\mathrm{SI} 5$ is based on strong interactions between $\mathrm{H}_{3}$ and $\mathrm{H}_{5}$ of aCD with the 
$\mathrm{H}_{15}$ of dehydro di-coniferyl alcohol (red double arrow). The orientation of dehydro di-coniferyl alcohol inside the ?CD cavity is based on the interaction of $\mathrm{H}_{6}^{\prime}$ and $\mathrm{H}_{3}{ }_{3}$ with $\mathrm{H}_{16}$ and $\mathrm{H}_{9}$, respectively (green double arrows). However, this deep inclusion concerns only one of the two stereoisomers since the other $\mathrm{H}_{15}$ presents lower cross peaks. Therefore, only the complex with the deepest inclusion is illustrated in Figure SI5.
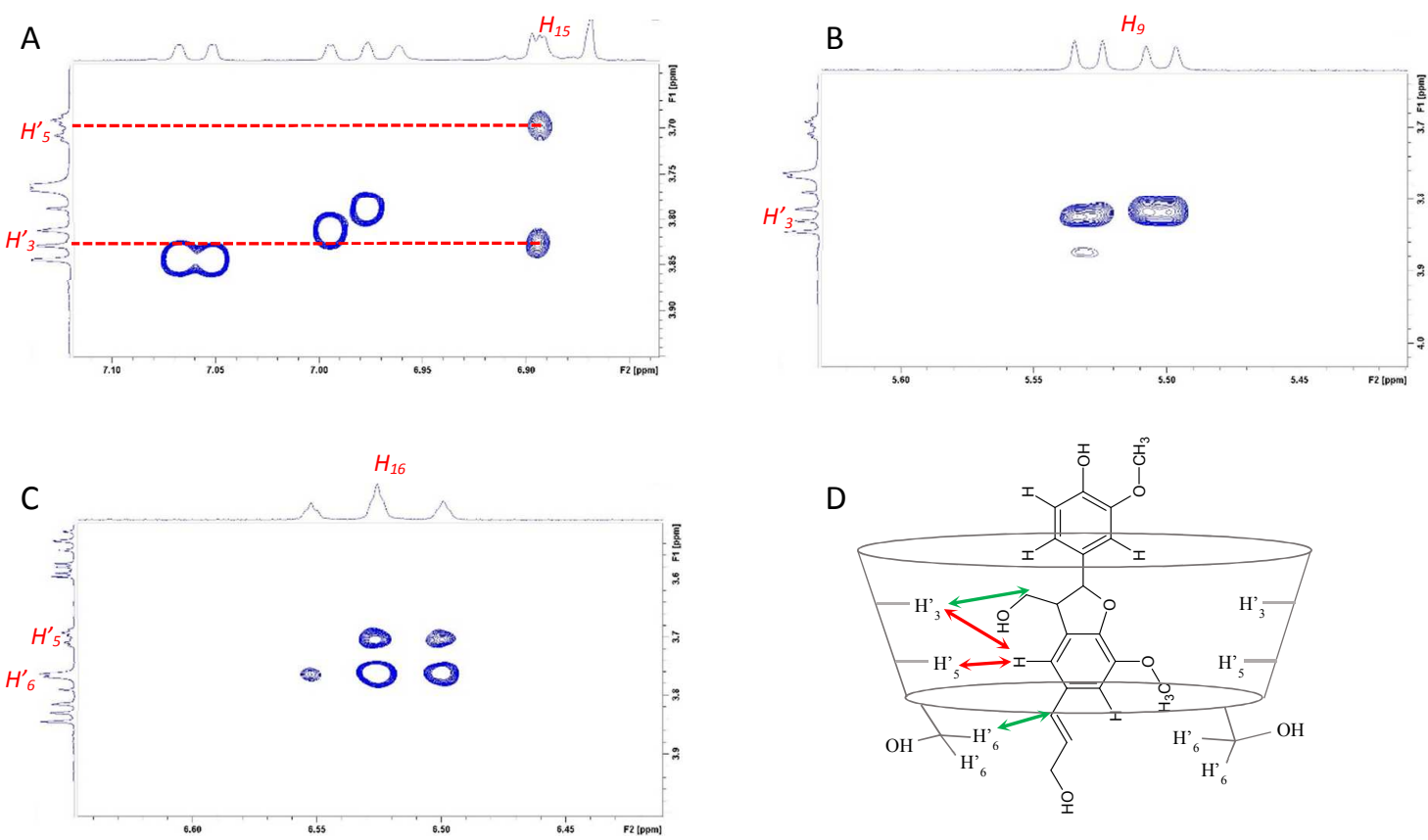

Figure SI5. Fragments of ROESY spectra showing the intermolecular interactions between protons from dehydro di-coniferyl alcohol and proton from $\beta C D$. Panel $A$, zoom in the interactions between the proton $\mathrm{H} 15$ of dehydro di-coniferyl alcohol and protons $\mathrm{H}^{\prime} 3$ and $\mathrm{H}^{\prime} 5$ of $\beta C D$; panel $\mathrm{B}, \mathrm{zoom}$ in the interactions between the proton $\mathrm{H} 9$ of dehydro di-coniferyl alcohol and protons $\mathrm{H}^{\prime} 3$ of $\beta C D$ (figure panel $\mathrm{D}$ ); panel $\mathrm{C}$, zoom in the interactions between the proton $\mathrm{H} 16$ of dehydro di-coniferyl alcohol and protons $\mathrm{H}^{\prime} 5$ and $\mathrm{H}^{\prime} 6$ of $\beta \mathrm{CD}$ (figure panel $D$ ); panel $D$, scheme of the potential interactions; double arrows indicate spatial dipolar interactions classified from each CD proton: close (red), intermediate (green).

\section{Evolution of lignans production as function of the initial coniferyl alcohol concentration}

Oxidation of coniferyl alcohol was performed and analysed as described earlier in the text (see paragraph 2). A typical reaction mixture $(1 \mathrm{~mL})$ contained LAC3 $(5 \mathrm{U} / \mathrm{L})$ coniferyl alcohol $(2.5,5$ or 10 $10^{-3} \mathrm{M}$ ) in the presence (or absence) of $1210^{-3} \mathrm{M}$ of $\beta C D$.

( \pm )-dehydrodiconiferyl alcohols

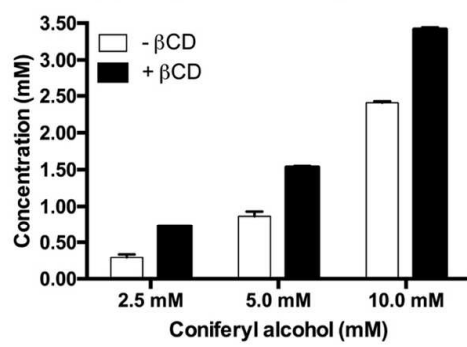

(土)-pinoresinols

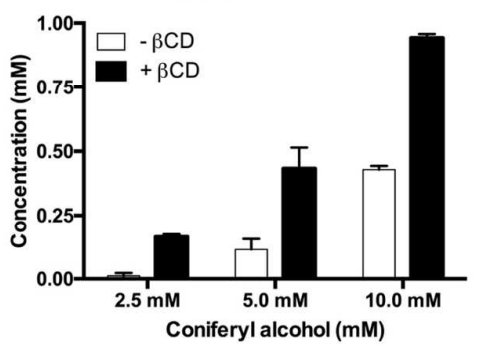

Figure SI6. Effects of a variable initial concentrations of coniferyl alcohol on the formation of dimeric lignans in the presence of $\beta C D$. 
1 Y. Mekmouche, S. M. Zhou, A. M. Cusano, E. Record, A. Lomascolo, V. Robert, A. J. Simaan, P. Rousselot-Pailley, S. Ullah, F. Chaspoul, T. Tron, J. Biosc. and Bioeng., 2014, 117, 25-27.

2 Kishimoto T., Takahashi N., Hamada M., Nakajima N., J. Agri. Food Chem., 2015, 63, 2277-2283.

3 W. Hinsberg, F. Houle. Kinetiscope ${ }^{\mathrm{TM}}$, a stochastic simulator v1.0.593.x64. C Columbia Hill Technical Consulting (2015)

4 Scott. R. L, Rec. Trav. Chem. Pays - Bas, 1956, 75, 787 - 789. 


\section{Journal Name}

\section{ARTICLE}

\section{Controlling the polymerization of coniferyl alcohol with cyclodextrins}

Received 00th January 20xx, Accepted 00th January 20xx

DOI: $10.1039 / x 0 x \times 00000 x$

www.rsc.org/
Lionel Tarrago*, Camille Modolo, Mehdi Yemloul, Viviane Robert, Pierre Rousselot-Pailley, Thierry Tron*

\section{Introduction}

Natural molecules such as sugars and amino acids are produced in cell as pure enantiomers by dedicated enzymes. One peculiar situation is however found in the synthesis of some plant metabolites (scheme 1) deriving from the monoelectronic oxidation of the lignol coniferyl alcohol (as the result from the activity of oxidases such as laccases) which leads initially to phenoxy radicals. ${ }^{1}$ In vitro a bimolecular radical coupling results in the transient accumulation of a mixture of ( \pm )-dehydrodiconiferyl alcohols (neo-lignan 2), ( \pm )-pinoresinols (lignan 3), and ( \pm )-guaiacylglycerol 8-0-4'-coniferyl alcohol ethers (neo-lignan 4) prior a further polymerization. In plants however either the $(+)$ - or $(-)$-enantiomer of pinoresinol is preferentially formed. ${ }^{2}$ Regio- and enantioselectivity are provided by dirigent proteins (DP) such as FiDIR1 and AtDIR6, which have been shown to be respectively responsible for the formation of (+)-pinoresinol in Forsythia intermedia ${ }^{2 a}$ and of ()-pinoresinol in Arabidopsis thaliana ${ }^{2 b}$. These proteins, which might not possess a catalytic center per se, are proposed to act as a scaffold interacting with radicals of coniferyl alcohol to direct the bimolecular coupling through a yet undetermined host/guest mechanism. In a bioconversion, the combined use of these proteins and a laccase or a chemical oxidant such as ammonium persulfate allows the enantioselective enrichment of pinoresinol. ${ }^{4}$

Produced from the enzymatic degradation of starch the

Aix Marseille Université, Centrale Marseille, CNRS, iSm2 UMR 731313397 Marseille (France).Emails : lioneltarrago@msn.com; thierry.tron@univ-amu.fr

+ Electronic Supplementary Information (ESI) available: Enzymes and chemicals; Synthesis of ( \pm )-guaiacylglycerol 8-0-4-coniferyl alcohol ethers (4); Coniferyl alcohol oxidation in the presence of $C D$; Fitting kinetics; Determination of the apparent association constant and complex structure by NMR; Evolution of lignans production as function of the initial coniferyl alcohol concentration. See DOI: $10.1039 / x 0 \times x 00000 x$

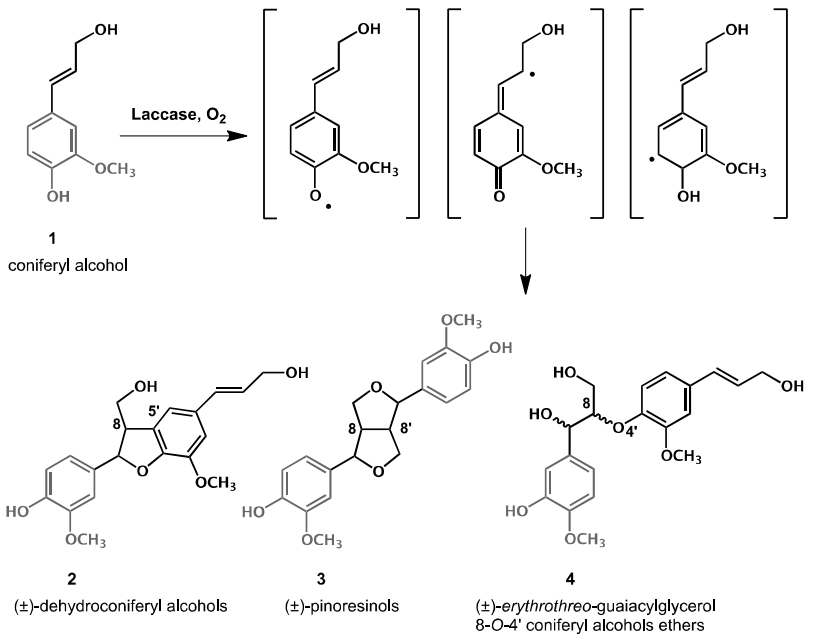

Scheme 1. Laccase catalysed oxidation of coniferyl alrohol

naturally occurring cyclic oligosaccharides cyclodextrins (CDs) share with DPs the ability to host guest molecules. Most commons CDs are made of $6(\alpha C D), 7(\beta C D)$ or $8(\gamma C D) \alpha-D-$ glucopyranoside units linked by $\alpha-1,4$ bonds. ${ }^{3}$ They have the form of truncated cones in which the hydroxyl groups are exposed to the solvent, making the exterior of the cone hydrophilic whereas the interior, considerably less hydrophilic than the aqueous environment, is able to host hydrophobic molecules. While the height of the torus remains constant $(0.79 \mathrm{~nm})$, the cavity diameter varies from $0.47-0.53 \mathrm{~nm}$ for the $\alpha C D, 0.6-0.65 \mathrm{~nm}$ for the $\beta C D$ and $0.75-0.83 \mathrm{~nm}$ for the $\gamma C D$. The internal cavity volume of $\alpha, \beta$ and $\gamma C D$ directly influences the size of the guest a CD molecule can accommodate. ${ }^{3}$ Because of these properties, CDs are used to 
enhance the solubility and bioavailability of numerous hydrophobic compounds such as drugs. ${ }^{3 d,}$ e Moreover, CDs can selectively bind chiral molecules and are used to produce commercial HPLC columns for enantiomers separation. ${ }^{4}$ Notably, in enantioselective synthesis, CDs or their derivatized forms have been shown to increase the enantiopure production of $\beta$-amino alcohols ${ }^{5}$ and to facilitate the enantioselective $\mathrm{N}$-acylation of primary amines ${ }^{6}$. CDs have been also shown to significantly improve enantiomeric excess in enzyme-catalysed reactions, such as the peroxidase catalysed synthesis of binaphthyl derivatives from naphtols and the esterase catalysed synthesis of the S-enantiomer of the anti-inflammatory drug naproxen. ${ }^{7}$

In this work, we studied the influence of CDs with different cavity volumes on the laccase-driven oxidation of coniferyl alcohol in bimolecular systems in which the substrate is mixed with an excess of CDs. We are clearly showing that while the dimerization of coniferyl alcohol is unaffected by the presence of $C D$ s, the $\beta C D$ cavity is stabilizing the lignan (3) and neolignans $(2,4)$ products and prevent their further oxidation by the enzyme. Moreover, amongst the three dimeric products generated the combination of laccase with $\beta C D$ allows a selective enrichment of pinoresinol, a behaviour somehow reminiscent of lignan synthesis in the presence of plant dirigent proteins.

\section{Results and Discussion}

In vitro oxidation of coniferyl alcohol 1 (3-(4-Hydroxy-3methoxyphenyl)-2-propen-1-ol) $\left(2.5 \times 10^{-3} \mathrm{M}\right)$ by the fungal laccase $\mathrm{LAC}{ }^{8}$ from Trametes sp. C30 $\left(5 \mathrm{U.L}^{-1}\right)$ generates lignans 2, $\mathbf{3}$ and $\mathbf{4}$ as initial products accumulating during the rapid phase of substrate consumption (see scheme 1). Influence of the CD cavity volume on the oxidation of 1 by LAC3 was evaluated in the presence of an excess $\left(12 \times 10^{-3} \mathrm{M}\right)$ of either $\alpha, \beta$ or $\gamma C D$. Both the consumption of 1 and the production of 2, $\mathbf{3}$ and $\mathbf{4}$ were followed as function of time by Reverse-Phase High Performance Liquid Chromatography (RP-HPLC). Analysis of the chromatograms is presented Figure 1. In the absence of $\mathrm{CDs}$, the kinetic of consumption of $\mathbf{1}$ follows a decreasing exponential with a consumption of nearly $90 \%$ of the substrate during the first hour (Fig. 1, graph (1)). In our experimental conditions $\mathbf{2}$ and $\mathbf{3}$ accounted for more than $80 \%$ of the dimers formed (Fig. 1, graphs (2) and (3))..$^{\ddagger}$ The neo-synthesized dimers 2, 3 and $\mathbf{4}$ containing phenolic moieties (i.e. a 2metoxyphenol), their concentration is rapidly high enough to compete with 1 as substrates for the LAC3 enzyme. Thus, after reaching a maximum (equilibrium between formation and disappearance) the concentration of $\mathbf{2}, \mathbf{3}$ and $\mathbf{4}$ was significantly decreasing with initial velocities of $c a .0 .16 \times 10^{-3}$ $\mathrm{mol} . \mathrm{L}^{-1} \cdot \mathrm{h}^{-1}(2)$ and ca. $0.10 \times 10^{-3} \mathrm{~mol} \cdot \mathrm{L}^{-1} \cdot \mathrm{h}^{-1}$ (3) ((Fig. 1, graphs (2) and (3)). As the reaction proceeds through mono-electronic oxidations, these observations are consistent with a further oxidation of the dimers 2,3 and 4 produced from coniferyl alcohol oxidation into polymers.

Evolution of the oxidation products was differentially influenced by the presence of $\alpha, \beta$ or $\gamma C D$ in the reaction mixture (Fig. 1). Addition of $\alpha C D$ to the reaction mixture had influence neither on the oxidation of $\mathbf{1}$ nor on that of the neosynthesized dimers. To the contrary, the presence of CDs with a larger cavity volume had a marked effect on the disappearance of the reaction products maintaining the concentration of $\mathbf{2}$ and $\mathbf{3}$ fairly stable around 80 to $85 \%$ of the maximum values for several hours without apparently affecting the oxidation rate of $\mathbf{1}$ (Fig. 1). Thus, addition of $\beta C D$ to the reaction mixture is stabilizing 2,3 and $\mathbf{4}$, probably forming $\beta-C D$ :dimer complexes that are significantly slowing down their further oxidation by the enzyme (vide infra).

Figure 1. Influence of $\mathrm{CDs}$ on the laccase catalysed oxidation of coniferyl alcohol. Coniferyl alcohol $(\mathbf{1})\left(2.5 \times 10^{-3} \mathrm{M}\right)$ was incubated with the laccase LAC3 $\left(5 \mathrm{U.L}^{-1}\right)$ at $30^{\circ} \mathrm{C}$ in the absence (open square) or presence of an excess $\left(12 \times 10^{-3} \mathrm{M}\right)$ of either $\alpha C D$ (crosses), $\beta C D$ (black circles) or $\gamma C D$ (black triangles). Consumption of $\mathbf{1}$ and apparition of $\mathbf{2}$ and $\mathbf{3}$ were monitored by RP-

(1)

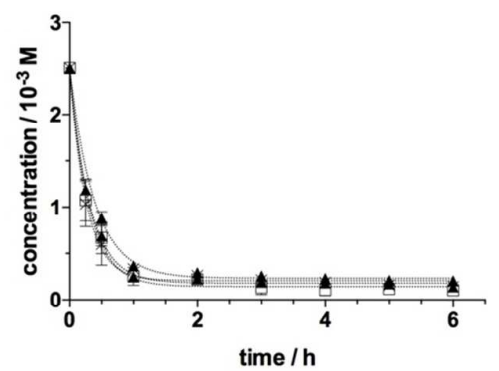

(2)

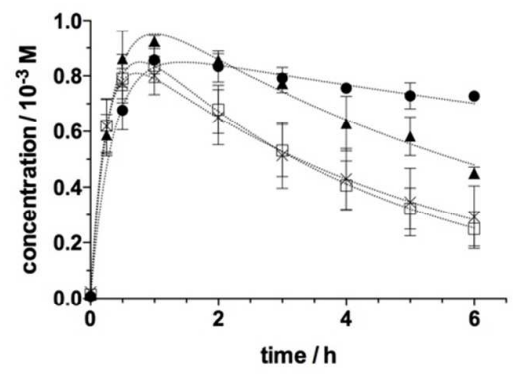

(3)

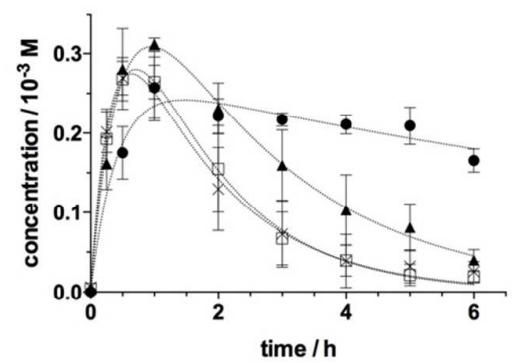

HPLC. Fits (dotted lines) were obtained either from a single decay (exponential) model (for the oxidation of 1) or are described in Supplementary Information.

In the presence of $\gamma C D$, the stabilization effect is clearly less pronounced as apparent initial rates of dimers oxidation were three times faster in the presence of $\gamma C D$ than in the presence of $\beta C D$ (ca. $0.09 \times 10^{-3} \mathrm{~mol} . \mathrm{L}^{-1} \cdot \mathrm{h}^{-1}$ vs. $0.03 \times 10^{-3} \mathrm{~mol} \cdot \mathrm{L}^{-1} \cdot \mathrm{h}^{-1}$ and $0.06 \times 10^{-3} \mathrm{~mol} . \mathrm{L}^{-1} \cdot \mathrm{h}^{-1}$ vs. $0.02 \times 10^{-3} \mathrm{~mol} \cdot \mathrm{L}^{-1} \cdot \mathrm{h}^{-1}$ for 2 and 3 respectively). Overall, in these experiments $\beta$ and $\gamma C D$ s have 
(2)

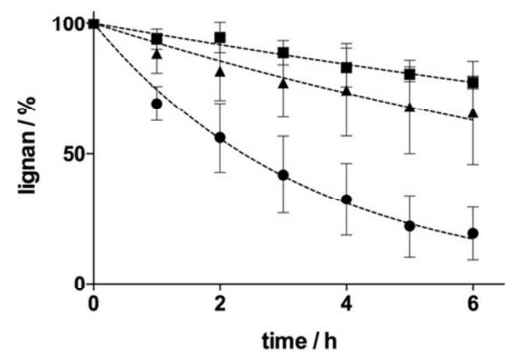

(3)

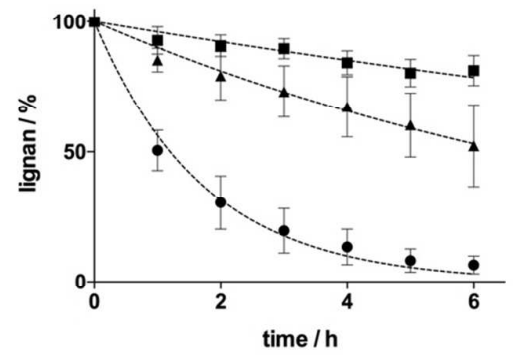

(4)

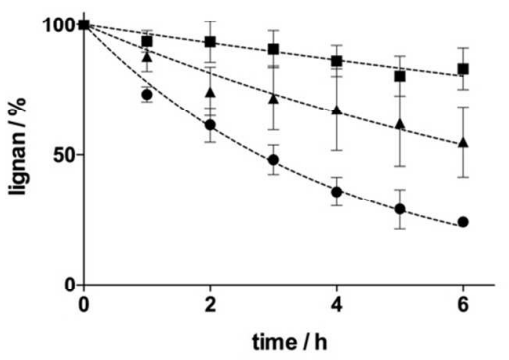

apparently no significant effect on the rate of oxidation of $\mathbf{1}$ and 4. whereas they have a marked effect on the stabilization of $\mathbf{2}, \mathbf{3}$

Figure 2. Influence of CDs on the laccase catalysed oxidation of the dimers 2, 3 and 4. Dehydroconiferyl alcohol (2), pinoresinol (3) or erythro guaiacyl glycerol $(4)\left(2.5 \times 10^{-3} \mathrm{M}\right)$ were each incubated with the laccase LAC3 $\left(5 \mathrm{U} . \mathrm{L}^{-1}\right)$ at $30^{\circ} \mathrm{C}$ in the absence $($ black circles) or presence of an excess $\left(12 \times 10^{-3} \mathrm{M}\right)$ of either $\beta C D$ (black squares) or $\gamma C D$ (black triangles). Oxidations were monitored by RP-HPLC. Fits (dashed lines) were obtained using a single decay (exponential) model.

Both the apparent complexity of the kinetics due to an oxidation of the products concomitant to their generation and the absence of exploitable data on the fate of the neo-lignan 4 lead us to further study the oxidation of pure dimers 2, 3 and $\mathbf{4}$ (see Supplementary Information for details about the origin of dimers). In the absence of $C D, \mathbf{3}$ is oxidized by laccase at a significantly faster rate than 2 and 4 (i.e. $1.3 \times 10^{-3}$ mol. $\mathrm{L}^{-1} \cdot \mathrm{h}^{-1}$ vs $0.7 \times 10^{-3} \mathrm{~mol} \cdot \mathrm{L}^{-1} \cdot \mathrm{h}^{-1}$ and $0.6 \times 10^{-3} \mathrm{~mol} \cdot \mathrm{L}^{-1} \cdot \mathrm{h}^{-1}$ respectively) the kinetics of oxidation of which were otherwise similar (Fig. 2). On the other hand, oxidation rates for $\mathbf{2 ,} \mathbf{3}$ and $\mathbf{4}$ are globally slower than the rate of oxidation of $\mathbf{1}$ (compare graph (1) from Fig. 1 and data (black circle) from Fig. 2). It is to note that these differences in kinetics are similar to those previously reported for the oxidation of $\mathbf{1}, \mathbf{2}, \mathbf{3}, \mathbf{4}$ by a peroxidase. ${ }^{9}$ Despite the fact that Matsushita and colleagues in the same article reported no difference in apparent oxidation potentials $\left(E^{o x}\right)$ for $\mathbf{1}, \mathbf{2}, \mathbf{3}, \mathbf{4}$, we cannot exclude here that these kinetic differences might be still mainly linked to different $E^{\circ}$ between dimers 2, 3, 4 and $\mathbf{1}$. Indeed, these electrochemical systems are irreversible as their oxidation is coupled to a chemical reaction (dimerization) and measuring their redox potentials $\left(E^{\circ}\right)$ requires specific setting and conditions (in particular very high scan rates). ${ }^{10}$

Cleared of the step corresponding to the dimerization of $\mathbf{1}$, the effects of CDs on laccase-mediated oxidation of 2, $\mathbf{3}$ or $\mathbf{4}$ are simpler to analyse. Regardless of their specific oxidation rates, the oxidation of each dimer $\mathbf{2}, \mathbf{3}$ or $\mathbf{4}$ was similarly slowed down in the presence of $\beta\left(0.04 \mathrm{~h}^{-1}\right.$ for all lignans) or $\gamma \mathrm{CD}(0.08$ to $0.1 \mathrm{~h}^{-1}$ ) suggesting a similar mode of interaction of the three different dimers with each of the CDs. As observed previously for the oxidation products of 1 (Fig. 1), $\gamma C D$ was less effective than $\beta C D$ in protecting dimers $\mathbf{2}, \mathbf{3}$ and $\mathbf{4}$ from oxidation.

The ability of a $C D$ to form an inclusion complex with a guest molecule is function both of a steric factor (the relative size of the $C D$ cavity to the size of the guest) and of a thermodynamic factor (a driving force bringing the guest into the cavity). ${ }^{11}$ Altogether, the differential effects induced by $\alpha, \beta C D$ or $\gamma C D$ on coniferyl alcohol and the neo-synthesized dimers oxidation

This journal is (C) The Royal Society of Chemistry 20xx match well both the physico-chemical properties of guests and CDs structural differences (i.e. cavity volume and rigidity). Dimers 2 to $\mathbf{4}$ contain each at least one aromatic 2metoxyphenol moiety inherited from their precursor the coniferyl alcohol molecule (1) (see scheme 1). The molecular volume of 2-metoxyphenol is estimated to be roughly $180 \AA^{3}$. Although an $\alpha-C D$ :coniferyl alcohol inclusion complex has been postulated from $1 \mathrm{D}{ }^{1} \mathrm{H}$ NMR experiments ${ }^{12}$ it seems that the internal cavity of $\alpha C D\left(174 \AA^{3}\right)$ might be eventually too small to stably accommodate neither the substrate nor the neosynthesized dimers. On the other hand, $\gamma\left(427 \AA^{3}\right)$ and $\beta(262$ $\AA^{3}$ ) CDs are both likely capable to accommodate molecules of the volume of guaiacol and larger. $A s \gamma C D$ is both larger and more flexible than $\beta C D, \gamma C D$ :dimer complexes are potentially less stable than $\beta C D$ :dimer complexes and that can account for observed kinetic differences. The absence of any "CD effect" on the oxidation kinetics of coniferyl alcohol (1) suggests that CDs may have a significantly less affinity for $\mathbf{1}$ than for the neosynthesized dimers. Excepting $\alpha C D$ the cavity of which is probably too small (vide supra), $\gamma$ and $\beta C D$ cavities could be too large to stabilize 1. Beyond the internal CD cavity volume, a simple examination of theoretical values describing the hydrophobic character and the water solubility of the ligand molecules point 1 as the least favourable ligand for forming an inclusion complex with $\mathrm{CDs}$ amongst the molecules we tested (3>2>4 $>\mathbf{1})$. $^{13}$

CD:guest complexes were studied by ${ }^{1} \mathrm{H}$ NMR experiments as their formation induce shifts of host and guest representative signals. Initially, the equilibrium between the constituents of a given complex was challenged in a titration of a low concentration of ligand (i.e. $500 \times 10^{-6} \mathrm{M}$ ) with increasing concentrations of CDs. Association constants $(K a)$ extracted

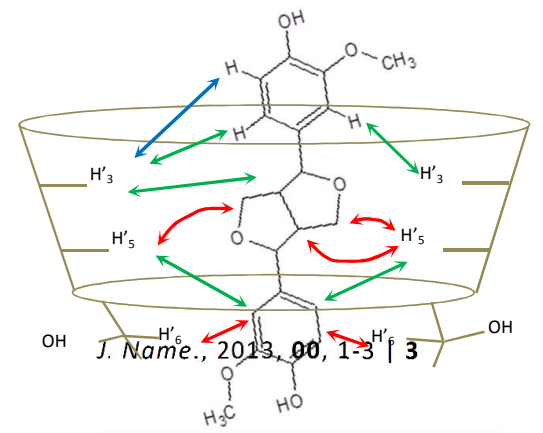


from Scott Plots $\left([C D]_{0} / \Delta \delta_{\text {obs }}=f\left([C D]_{0}\right)\right.$, see Supplementary information Fig. SI2 for details) are presented in Table 1. Reflecting a dynamic exchange in CD:guest complexes $K a$ values are notoriously fairly low. ${ }^{11 a}$ As expected, values for $\gamma C D$ are lower than those calculated for $\beta C D$. Nevertheless, amongst complexes the apparent hierarchy $\mathbf{3}: C D>2: C D>\mathbf{4}: C D$ $>1: \mathrm{CD}$ matches that deduced from theoretical physicochemical properties of ligands (vide supra). Ka values for a potential 1:CD complex are extremely low and their significance questionable. Both the absence of substantial effect on the oxidation rate of $\mathbf{1}$ (see Fig. 1) and low Ka values strongly support that $\mathbf{1}$ is not forming stable complexes with CDs.

Table 1. Association constants $\left(\mathrm{M}^{-1}\right)$ measured for lignans/CD complexes.

\begin{tabular}{ccc}
\hline Entry & $\beta C D$ & $\gamma C D$ \\
\hline $\mathbf{1}$ & 439 & 196 \\
$\mathbf{2}$ & 1065 & 269 \\
$\mathbf{3}$ & 1281 & 750 \\
$\mathbf{4}$ & 808 & 392 \\
\hline
\end{tabular}

In addition, plotting the extend of the shifts as function of the evolution of the molar ratio between the $C D(\beta$ or $\gamma C D)$ and the guest suggested a 1:1 stoichiometry for all the $C D$ :guest complexes studied (see Fig. SI3). Next, we used Rotating frame nuclear Overhauser Effect SpectroscopY (2D-ROESY) experiments to further characterize 1, 2, 3 and 4: $\beta C D$ inclusion complexes. Highlighting intra and inter-molecular spatial proximity (below $6 \AA \AA$ ) the Nuclear Overhauser Effect is widely used for the characterization of host-guest intermolecular interactions. ${ }^{14}$ Globally, disregarding relaxation and molecular motions, in the phase sensitive 2D-ROESY experiments ${ }^{15}$ the integrated intensity of the cross-peaks is directly correlated with the inter-nuclear distance of the two observed protons. Beyond the observation of ${ }^{1} \mathrm{H}$ chemical shift displacements of host and/or guest molecules as often found in descriptions of ligand:CD complexes, this approach allows a more accurate description of inclusion complexes classifying interatomic distances from each $\beta C D$ proton. For each complex, we studied the cross peaks involving $\mathrm{H}^{\prime} 3$ and $\mathrm{H}^{\prime} 5$ protons from the inside of the CDs cavity and the $\mathrm{H}^{\prime} 6$ proton located out at the narrow rim (crown). 2D-ROESY spectra in which the intermolecular cross-peaks are highlighted are presented in supplementary information (Fig. SI4 and SI5). These NMR data are consistent with a potential insertion of lignans 2, $\mathbf{3}$ or $\mathbf{4}$ into the $\beta C D$ cavity and their stabilization at the narrow rim. A scheme of a potential inclusion complex reflecting correlations observed between protons $\mathrm{H} 2, \mathrm{H} 5, \mathrm{H} 6$ of 3 and protons $H^{\prime} 3, H^{\prime} 5, H^{\prime} 6$ of $\beta C D$ is proposed in Figure 3. However, as CD may also form non-inclusion complexes with guest molecules, ${ }^{3}$ a stabilization of dimers $2, \mathbf{3}$ and $\mathbf{4}$ at the narrow rim but outside the cavity cannot be formally ruled out. Whatever their structure (i.e. inclusion or non-inclusion), $\beta C D$ :guest complexes stabilize dimers 2,3 and $\mathbf{4}$ thereby offering them a protection against oxidation.

Figure 3. Schematic view of a potential $\beta C D /( \pm)$-pinoresinol inclusion complex as deduced from 2D-ROESY data. Double arrows indicate spatial dipolar interactions classified from each CD proton: close (red), intermediate (green), far (blue).

Considering the above results, only $\beta C D$ was further investigated. Proportions of dimers 2, 3 and $\mathbf{4}$ derived from the oxidation of $\mathbf{1}$ were found insensitive to a variation of the $\beta-C D$ concentration (0-13 $10^{-3} \mathrm{M}$ range). Whereas in several cases of catalysed reactions the presence of $\beta C D$ has been shown to influence the selectivity ${ }^{5-7,16-20}$, there is here no selectivity in the oxidation of $\mathbf{1}$ (as assessed by separation of the neosynthesized dimeric products on a chiral column) simply because 1 is not (or too weakly) interacting with the CD. Besides, amounts of $\mathbf{2}$ and $\mathbf{3}$ remaining non-oxidized in the reaction mixture were found to follow a saturation profile as the concentration of $\beta C D$ increased (Fig. 4).

Figure 4. Influence of varying the concentration of $\beta C D$ on final concentrations of dimers $\mathbf{2}$ and $\mathbf{3}$. Dimers $\mathbf{2}$ and $\mathbf{3}(2.5 \mathrm{x}$ $\left.10^{-3} \mathrm{M}\right)$ were incubated with the laccase LAC3 $\left(5{\left.\mathrm{U} . \mathrm{L}^{-1}\right)}^{-1}\right) 30^{\circ} \mathrm{C}$ in the presence of variable concentrations $\left(0-13 \times 10^{-6} \mathrm{M}\right)$ of $\beta C D$ for 6 hours. $C=$ dimer concentration in the absence of $\beta C D ; C_{\beta}=$ dimer concentration in the presence of $\beta C D$. Fits (dotted lines) were obtained using a one-phase association (exponential) model.

Comparatively, the amplitude of the variation in dimer

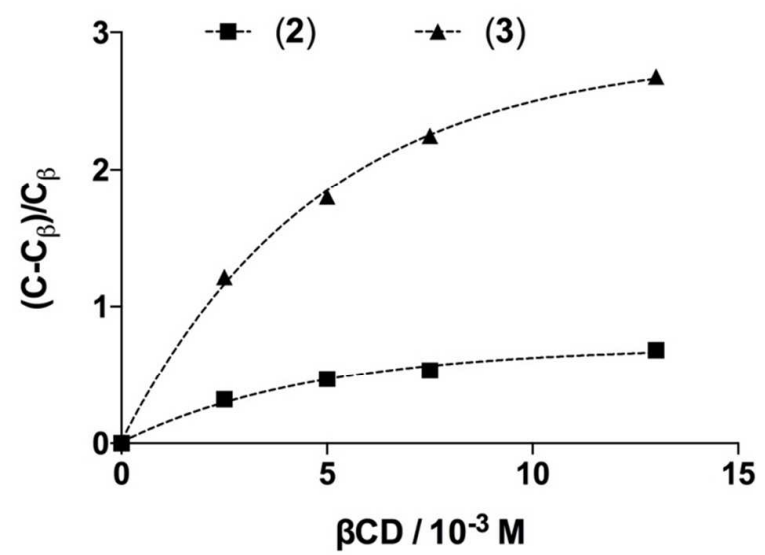

concentrations in the presence of $\beta C D$ versus in the absence of $\beta C D$ is higher for dimer $\mathbf{3}$ than for dimer $\mathbf{2}$ (note that the concentration of $\mathbf{4}$ was too low be properly analysed). Since oxidation rates of dimers $\mathbf{2}$ and $\mathbf{3}$ obtained in the presence of $\beta C D$ are quite similar (see Fig. 2), this behaviour is totally attributable to differences in oxidation rates of the dimers by the enzyme alone. On the other hand, the protective effect of $\beta C D$ on dimer oxidation decreased as the initial concentration of 1 increased (Fig. SI6). This is both related to the rate of dimer synthesis and to the formation of dimer:CD complexes that is limited by the concentration of $\beta C D\left(12-13 \times 10^{-3} \mathrm{M}\right)$. With a LAC3 apparent Michaelis constant $\left(K_{\text {Mapp }}\right)$ value 
estimated around $10 \times 10^{-3} \mathrm{M}$ for $\mathbf{1}$, the rate of dimer formation is likely not maximal at low concentrations of $\mathbf{1}$ (e. $\mathrm{g}$. $2.5 \times 10^{-3} \mathrm{M}$ ). All the neo-synthetized dimers produced are probably forming a complex with $\beta C D$ molecules which protects them from a further oxidation by LAC3. As the concentration of 1 increases, the neo-synthetized dimers 2, 3 and 4 accumulate and there is a competition between dimer: $\beta C D$ complexes formation and oxidation of the neosynthetized dimers by LAC3.

CDs are known to interact with the surface of macromolecules, a property often used to stabilize these objects. ${ }^{21}$ Beyond a sequestration of the substrate ${ }^{22}$ that is apparently here not influencing the fate of $\mathbf{1}$ (vide supra), a direct laccase:CD interaction was challenged. Whether or not $\beta C D$ interferes with the oxidation of 1 by LAC3 (pseudo competition) was tested recording enzyme kinetics in the presence of increasing concentrations of $\beta C D$. $\beta C D$ had no influence on initial rates of consumption of 1. Neither it has an influence on initial rates of production of dimers as dimerization occurs through a radicalradical coupling independent of the presence of the enzyme. Therefore, in the oxidation of $1, \beta C D$ is not a modulator of the laccase activity neither through the formation of a complex with 1 or through a direct CD:enzyme interaction. This leaves that the observed stabilisation of the dimers is entirely due to their interaction with the $\beta C D$.

\section{Experimental}

All chemicals were purchased from Sigma-Aldrich and used as received except for $\beta C D$ which was recrystallized twice in $60 \%$ ethanol. The laccase LAC3 (from Trametes sp C30) ${ }^{8 a}$ was produced in Aspergillus niger and purified as previously described ${ }^{8 \mathrm{~b}}$. Oxidation of coniferyl alcohol was performed with laccase at $30^{\circ} \mathrm{C}$ in BrittonRobinson buffer adjusted at $\mathrm{pH} 5.0$ and oxidation products were separated by reverse phase HPLC. All NMR experiments were performed at $298 \mathrm{~K}$ in $\mathrm{D}_{2} \mathrm{O}$ on a Bruker Avance III $600 \mathrm{MHz}$ spectrometer, equipped with a $5 \mathrm{~mm}$ triple resonance high resolution probe. All NMR datasets were processed in TOPSPIN 3.2 version (Bruker BioSpin, Germany).

\section{Conclusions}

The use of cyclodextrins in the laccase catalysed oxidation of coniferyl alcohol allows a control of the polymerisation by a stabilisation of the dimers resulting from radical coupling. Stabilisation goes through complexes depending on the size of the $C D$ cavity and is maximum for $\beta C D$. Whereas a $C D$ :coniferyl alcohol inclusion complex is not forming in the catalytic conditions used, all three dimeric product (one lignan and two neo-lignans) are protected from further oxidation by the enzyme through a complexation by CDs. As the oxidation rate of the unprotected $( \pm)$ pinoresinol is faster than that of the other dimeric products, the formation of a complex with $\beta C D$ induces an apparent bias in the relative proportions of dimers. So, amongst the three dimeric products generated the laccase- $\beta C D$ system allows a selective enrichment of pinoresinol, a behaviour somehow resembling that of plant dirigent proteins. $^{2}$ Overall, results obtained from this study point a selective interaction of $\mathrm{CDs}$ with lignan and neo-lignan molecules and open the possibility to use CDs to control the polymerization process of lignans or related phenolic molecules for the synthesis of molecules of interest.

\section{Conflicts of interest}

There are no conflicts to declare.

\section{Acknowledgements}

This study was supported by funds from the CNRS and Aix Marseille Université and from a grant from the Agence Nationale de la Recherche (ANR-09-BLANC-0176). CM is a recipient of a fellowship from the Fondation Pierre Pottier. We thank Elise Courvoisier-Dezord from the Plateforme AVB (AMU): Analyse et Valorisation de la Biodiversité and Yolande Charmasson for help in the production of the recombinant enzymes. We also thank Frédéric Turpin and El Mustapha Belgsir (Biocydex Ltd) as well as Ariane J. Simaan for helpful discussions.

\section{Notes and references}

$¥$ In the conditions chosen for a maximum separation of $\mathbf{2}$ and $\mathbf{3}$, peaks of 1 (decreasing) and 4 (increasing) were coincidental, both preventing a precise follow up of the kinetics of the appearance of the minor product $\mathbf{4}$ and introducing a bias in the evaluation of the concentration of 1 . Although the effect is minor for the interpretation of the kinetics for $\mathbf{2}$ and $\mathbf{3}$ this has to be stated here.

1 C. Paniagua, A. Bilkova, P. Jackson, S. Dabravolski, W. Riber, V. Didi, J. Houser, N. Gigli-Bisceglia, M. Wimmerova, E. Budinska, T. Hamann, J. Hejatko, J. Exp. Botany, 2017, 68, 3287.

2 a) L. B. Davin, H. B. Wang, A. L. Crowell, D. L. Bedgar, D. M. Martin, S. Sarkanen, N. G. Lewis, Science 1997, 275, 362; b) B. Pickel, M. A. Constantin, J. Pfannstiel, J. Conrad, U. Beifuss, A. Schaller, Angew. Chem. Int. Edit., 2010, 49, 202.

3 a) H. Dodziuk, in Cyclodextrins and Their Complexes, Wiley-VCH Verlag GmbH \& Co. KGaA, 2006, pp. 1-30; b) S. Divakar, M. S. Narayan, A. K. Shaw, Indian J. Chem. B 1993, 32, 387; c) J. Szejtli, Chem. Rev. 1998, 98, 1743-1753; d) M. E. Brewster, T. Loftsson, Adv. Drug. Deliver. Rev., 2007, 59, 645; e) T. Loftsson, D. Hreinsdottir, M. Masson, Int. J. Pharm., 2005, 302, 18.

4 a) D. W. Armstrong, M. Hilton, L. Coffin, LC Gc-Mag. Sep. Sci., 1991, 9, 646; b) A. Motoyama, A. Suzuki, O. Shirota, R. Namba, J. Pharmaceut. Biomed., 2002, 28, 97.

5 L. R. Reddy, N. Bhanumathi, K. R. Rao, Chem. Comm. 2000, 2321.

6 H. Asahara, T. Kida, T. Iwamoto, T. Hinoue, M. Akashi, Tetrahedron, 2014, 70, 197.

7 F. Trotta, L. Costa, G. Cravotto, J. Incl. Phenom. Macro. 2002, 44, 341. 
8 a) A. Klonowska, C. Gaudin, M. Asso, A. Fournel, M. Reglier, T. Tron, Enzyme Microb. Tech., 2005, 36, 34; b) Y. Mekmouche, S. Zhou, A. M. Cusano, E. Record, A. Lomascolo, V. Robert, A. J. Simaan, P. RousselotPailley, S. Ullah, F. Chaspoul, T. Tron, J. Biosci. Bioeng., 2014, 117, 25.

9 Y. Matsushita, C. Ko, D. Aoki, S. Hashigaya, S. Yagami, K. Fukushima, J. Wood. Sci., 2015, 61, 608.

10 P. Hapiot, J. Pinson, P. Neta, C. Francesch, F. Mhamdi, C. Rolando, S. Schneider, Phytochem., 1994, 36, 1013.

11 a) K. A. Connors, Chem Rev 1997, 97, 1325; b) E. M. M. Del Valle, Process Biochem., 2004, 39, 1033.

12 R. Nakamura, Y. Matsushita, K. Umemoto, A. Usuki, K. Fukushima, Biomacromolecules, 2006, 7, 1929.

13 a) I. V. Tetko, J. Gasteiger, R. Todeschini, A. Mauri, D. Livingstone, P. Ertl, V. Palyulin, E. Radchenko, N. S. Zefirov, A. S. Makarenko, V. Y. Tanchuk, V. V. Prokopenko, J. Comput. Aid. Mol. Des., 2005, 19, 453; b) VCCLAB, Virtual Computational Chemistry Laboratory, http://www.vcclab.org, 2005.

14 H. J. Schneider, F. Hacket, V. Rudiger, H. Ikeda, Chem. Rev., 1998, 98, 1755.

15 a) A. Bax, D. G. Davis, J. Magn. Reson., 1985, 63, 207; b) T. L. Hwang, A. J. Shaka, J. Am. Chem. Soc., 1992, 114, 3157.

16 a) R. Breslow, P. Campbell, J. Am. Chem. Soc., 1969, 91, 3085; b) M. Komiyama, J. Chem. Soc. Chem. Comm. 1988, 651.

17 A. Ghanem, Org. Biomol. Chem., 2003, 1, 1282.

18 M. Singh, R. Sharma, U. C. Banerjee, Biotechnol. Adv., 2002, 20, 341.

19 R. Villalonga, R. Cao, A. Fragoso, Chem. Rev., 2007, 107, 3088.

20 R. Ravichandran, S. Divakar, J. Inclus. Phenom. Mol., 1993, 16, 201.

21 a) K. Griebenow, Y. D. Laureano, A. M. Santos, I. M. Clemente, L. Rodríguez, M. W. Vidal, G. Barletta, J. Am. Chem. Soc., 1999, 121, 8157; b) S. Schmitz, H. Ritter, Angew. Chem. Int. Ed., 2005, 44, 5658; c) T. Serno, R. Geidobler, G. Winter, Adv. Drug. Deliver. Rev., 2011, 63, 1086.

22 a) P. L. Irwin, P. E. Pfeffer, L. W. Doner, G. M. Sapers, J. D. Brewster, G. Nagahashi, K. B. Hicks, Carbohyd. Res., 1994, 256, 13; b) M. M. Sojo, E. Nunez-Delicado, F. Garcia-Carmona, A. Sanchez-Ferrer, J. Agr. Food. Chem. 1999, 47, 518; c) E. Nunez-Delicado, M. M. Sojo, A. Sanchez-Ferrer, F. Garcia-Carmona, Arch. Biochem. Biophys. 1999, 367, 274; d) E. Orenes-Pinero, F. GarciaCarmona, A. Sanchez-Ferrer, J. Mol. Catal. B-Enzym., 2007, 47, 143. 


\title{
Controlling the polymerization of coniferyl alcohol with cyclodextrins.
}

\author{
Lionel Tarrago*, Camille Modolo, Mehdi Yemloul, Viviane Robert, Pierre Rousselot-Pailley, Thierry Tron* \\ Aix Marseille Université, CNRS, iSm2 UMR 7313, 13397, Marseille, France \\ * Corresponding authors: Lionel Tarrago, Thierry Tron \\ E-mail address: lioneltarrago@msn.com; thierry.tron@univ-amu.fr
}

\section{Supplementary Information}

\section{Enzymes and chemicals}

The laccase LAC3 (from Trametes sp C30) was produced in Aspergillus niger and purified as described previously. ${ }^{1}$ Protein concentration was estimated by UV-visible spectroscopy using an $\varepsilon_{600 \mathrm{~nm}}=5 \times 10^{3} \mathrm{M}^{-1} \cdot \mathrm{cm}^{-1}$ for the T1 copper. Laccase activity of the purified protein solution was assayed using 2,2'-azino-bis(3-ethylbenzthiazoline-6-sulphonic acid) (ABTS). One unit (U) of laccase oxidizes one micromole of ABTS per minute.

Alpha-cyclodextrin $(\alpha C D)$, beta-cyclodextrin $(\beta C D)$ and gamma-cyclodextrin $(\gamma C D)$ were obtained from Aldrich or $\mathrm{TCl}$ Europe. Beta-cyclodextrin $(\beta C D)$ was recrystallized twice in $60 \%$ ethanol. Dehydrodiconiferyl alcohols (2) and ( \pm )-pinoresinols (3) were obtained from the bioconversion of coniferyl alcohol (1) (purchased from Sigma France) catalysed by the enzyme LAC3, purified by preparative chromatography (silica) and characterized by ${ }^{1} \mathrm{H}$ NMR and mass spectrometry. All other chemicals were purchased from Sigma France.

\section{Synthesis of ( \pm )-guaiacylglycerol 8-0-4'-coniferyl alcohol ethers (4)}

4 was obtained by oxidation of 1 in the presence of silver oxide $\left(\mathrm{Ag}_{2} \mathrm{O}\right)$ following a protocol described Kishimoto et al., $2015 .^{2}$ The product of interest was purified by preparative chromatography (silica) and characterized by ${ }^{1} \mathrm{H}$ NMR and mass spectrometry.

\section{Coniferyl alcohol oxidation in the presence of $C D$}

Oxidation of coniferyl alcohol was performed at $30^{\circ} \mathrm{C}$ in Britton-Robinson buffer adjusted at pH 5.0 and oxidation products were detected by reverse phase HPLC. A typical reaction mixture $(1 \mathrm{~mL})$ contained LAC3 $(5 \mathrm{U} / \mathrm{L})$ and coniferyl alcohol $\left(2.510^{-3} \mathrm{M}\right)$ in the absence or presence of CD (up to 12 $10^{-3} \mathrm{M}$ ). The reaction proceeded for 8-hours and was initiated by the addition of the enzyme. For each time-point, the reaction was stopped by mixing $100-\mu \mathrm{L}$ aliquot to $100 \mu \mathrm{L}$ acetonitrile containing $2.85 \mathrm{mM}$ benzophenone. $30 \mu \mathrm{L}$ was injected on C18 column (EC150/4 Nucleosil ${ }^{\circledR} 100-5-18$ MachereyNage $^{\mathrm{TM}}{ }^{\text {) }}$ and analyzed by HPLC (Waters ${ }^{\mathrm{TM}}$ Alliance $^{\circledR}$ 2690/2690D Separations Module) with the following gradient: solvent $A$ water containing $3 \%$ acetic acid, solvent $B$ acetonitrile; $t=0 \mathrm{~min} 90 \% A$ $10 \% \mathrm{~B}, \mathrm{t}=5 \mathrm{~min} 90 \% \mathrm{~A} 10 \% \mathrm{~B}, \mathrm{t}=25 \mathrm{~min} 50 \% \mathrm{~A} 50 \% \mathrm{~B}, \mathrm{t}=27 \mathrm{~min} 50 \%$ A 50\% B, $\mathrm{t}=28 \mathrm{~min} 90 \% \mathrm{~A} 10 \% \mathrm{~B}$, $\mathrm{t}=30 \mathrm{~min} 90 \% \mathrm{~A} 10 \% \mathrm{~B}$. Coniferyl alcohol, dehydrodiconiferyl alcohol, pinoresinol and benzophenone were eluted at $4.0 \mathrm{~min}, 6.6 \mathrm{~min}, 8.2 \mathrm{~min}$ and $16.6 \mathrm{~min}$, respectively. Quantity was normalized using benzophenone as internal reference.

Apparent $K_{M}$ and $k_{c a t}$ values were obtained from the initial rate $(v)$, enzyme concentration (E) and substrate concentration (S) according to the equation $v=k_{\text {cat }} \mathrm{ES} /\left(K_{M}+\mathrm{S}\right)$. Inhibition kinetics data were obtained using appropriate equations. All data were determined using non-linear regression fitting using Prism software, Graphpad, San Diego, (CA). Because laccase catalysis involves two 
substrates and the $\left[\mathrm{O}_{2}\right]$ was invariant and assumed to be saturating in this study, the measured $K_{M}$ for the various substrates used should be considered apparent. Because of the assumption that $100 \%$ of the laccase participated in the catalysis as active enzyme, the measured $k_{\text {cat }}$ should also be considered apparent.

\section{Fitting kinetics}

The oxidation of coniferyl alcohol (1) by the enzyme laccase is a mono-electronic process leading to the transient formation of a radical species $\left(1^{\circ}\right)$ (eq. 1 ). Radical molecules recombine to give dimers 2, 3 and $\mathbf{4}$ according to eq. 2. Dimers are themselves subsequently oxidized by the enzyme (eq. 2, 4, 5) in a reaction similar to the oxidation of 1.

$$
\begin{aligned}
& 1 \frac{k_{1}}{-\mathrm{H}^{+}-\mathrm{e}^{-}} \mathbf{1}^{\cdot} \\
& n \mathbf{1}^{\bullet} \stackrel{k_{d i m}}{\longrightarrow} m \mathbf{2}+k \mathbf{3}+l \mathbf{4} \\
& 2 \frac{k_{2}}{-\mathrm{H}^{+}-\mathrm{e}^{-}} \mathbf{2}^{\cdot} \\
& \left.3 \underset{-\mathrm{H}^{+}-\mathrm{e}^{-}}{\stackrel{k_{3}}{-}} \quad \text { (eq. } 4\right) \\
& 4 \underset{-\mathrm{H}^{+}-\mathrm{e}^{-}}{\stackrel{k_{4}}{-}} 4^{\cdot} \quad \text { (eq. 5) }
\end{aligned}
$$

Kinetic data presented in Figure 1 from the main article were simulated using the stochastic kinetics simulator Kinetiscope (freeware) ${ }^{3}$. In the simulation, we introduced:

- the initial concentration of coniferyl alcohol [1] $=2.510^{-3} \mathrm{M}$

- rate constants from (eq. $1,3,4,5$ ) initially derived from experimental data presented in Fig. 1 and Fig. 2 from the main article: $k_{1}=3.3 \mathrm{~h}^{-1} ; k_{2}=0.3 \mathrm{~h}^{-1} ; k_{3}=0.5 \mathrm{~h}^{-1} ; k_{4}=0.25 \mathrm{~h}^{-1}$

- a bi-molecular constant $k_{\text {dim }}$ from (eq. 2) arbitrary set to a value of $>k_{1}, k_{2}, k_{3}, k_{4}$ (i.e.10 $10^{6} \mathrm{M}^{-1}$. $\left.\mathrm{h}^{-1}\right)$. With this approximation we recognize the recombination of radicals as a process considerably faster than oxidation steps and we do not distinguish the formation of each dimer 2, 3 and $\mathbf{4}$ (eq. 2).

The model obtained (Fig. SI1) is compatible with experimental data (Fig. 1 main text).

\section{simulation}

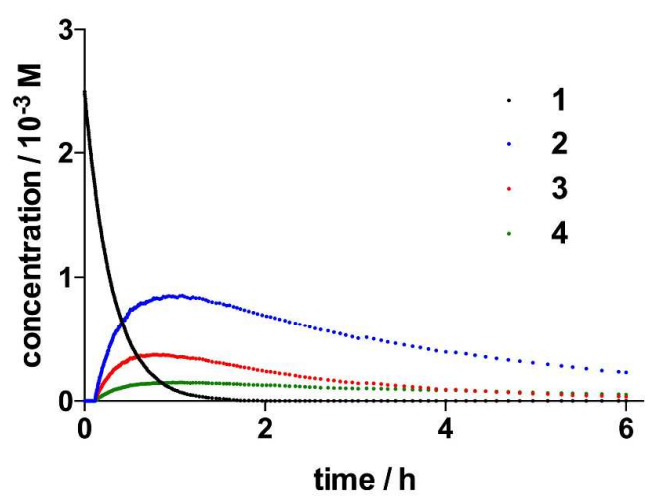

Figure SI1. Simulation of the formation of lignans from the oxidation of coniferyl alcool. Stochastic calculations performed with the freeware Kineticsope. Initial parameters: $[1]=2.510^{-3} \mathrm{M}, k_{1}=3.3 \mathrm{~h}^{-1} ; k_{2}=0.3$ $\mathrm{h}^{-1} ; k_{3}=0.5 \mathrm{~h}^{-1} ; k_{4}=0.25 \mathrm{~h}^{-1}$. 
Eventually, kinetics of the two successive oxidations leading to the formation and to the disappearance of each dimer (see Fig. 1 panels 2 and 3 main text) can be fitted using the simple model:

$$
\mathrm{A} \stackrel{k_{1}}{\longrightarrow} \mathrm{B} \stackrel{k_{2}}{\longrightarrow} \mathrm{C}
$$

treated as a succession of order 1 kinetics in which the dimerization step is not influencing the rate (i.e. $k_{\text {dim }}>k_{1}, k_{2}$ ).

$$
\mathrm{Y}=\left(\left(\mathrm{a} * k_{1}\right) /\left(k_{2}-k_{1}\right)\right) *\left(\exp \left(-k_{1} * \mathrm{X}\right)-\exp \left(-k_{2} * \mathrm{X}\right)\right)
$$

with $k_{1}=$ rate constant for the oxidation of the alcohol and $k_{2}=$ rate constant for the oxidation of the dimer.

\section{Determination of the apparent association constant and complex structure by NMR}

All experiments were performed at $298 \mathrm{~K}$ in $\mathrm{D}_{2} \mathrm{O}$ on a Bruker Advance III $600 \mathrm{MHz}$ spectrometer, equipped with a $5 \mathrm{~mm}$ triple resonance high resolution probe. All NMR datasets were processed in TOPSPIN 3.2 version (Bruker BioSpin, Germany). Proton NMR spectra were acquired with a spectral width of $6000 \mathrm{~Hz}$ and relaxation delay of 2s during which a water pre-saturation was applied.

$K a$ values were extracted from Scott plots $\left([C D]_{t} /\right.$ ? ? $\left.\left.\left._{\mathrm{obs}}=\left([C D]_{\mathrm{t}} / \text { [? }\right]_{\mathrm{c}}\right)+(1 / \mathrm{Ka} \text { ? }]_{\mathrm{c}}\right)\right){ }^{4}$

$\delta I=$ chemical shift of a proton from the ligand or from the free CD.

$\delta c=$ chemical shift of the same proton in the ligand:CD complex.

$\Delta \delta$ obs $=\delta \mathrm{I}-\delta \mathrm{c}$

Plots for $\beta C D$ complexes are given in Figure SI2.

(1)

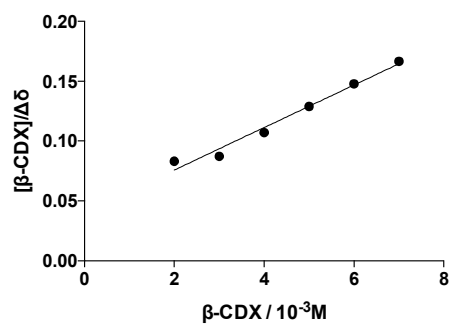

(3)

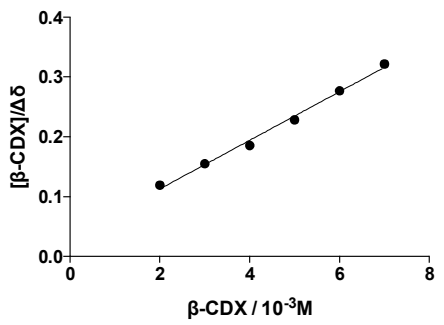

(2)

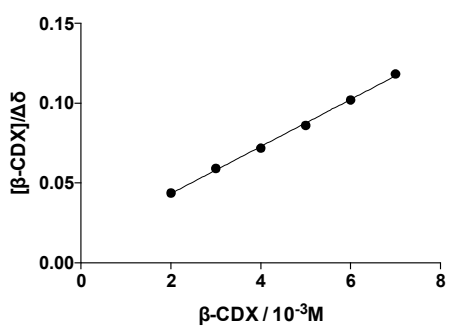

(4)

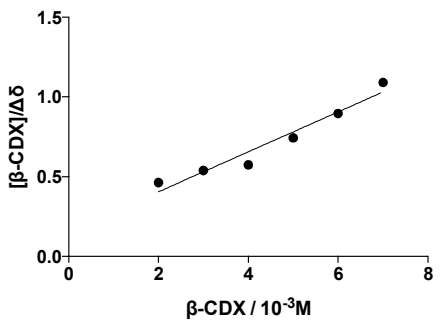

Figure S12. Representation of the ligand: $\beta C D$ interaction (Scott plots). [Ligand] $=0.510^{-3} \mathrm{M},[\beta C D]=2-710^{-3} \mathrm{M}$.

The stoichiometry for all the CD:guest complexes was studied plotting the extend of the shifts as function of the evolution of the molar ratio between the $C D$ ( $\beta$ or $\gamma C D$ ) and the ligand (Job Plots). Plots for $\beta C D$ complexes are given in Figure SI3. 
For complex structure analysis, 2D phase-sensitive ROESY were acquired by pulse field gradientselected methods, with 32 scans and 2048-time domain in F2, and 384 experiments in F1 by using the TPPI method and a mixing time (spin-lock) of $200 \mathrm{~ms}$ at a field of $6 \mathrm{kHz}$.

(1)

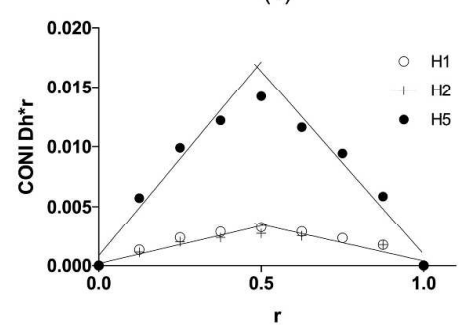

(3)

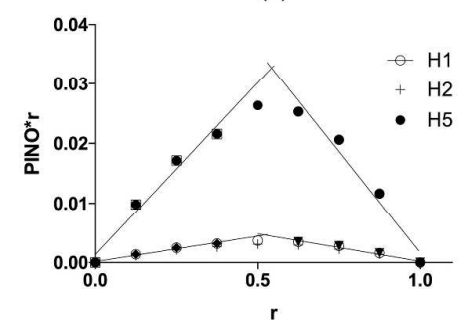

(2)

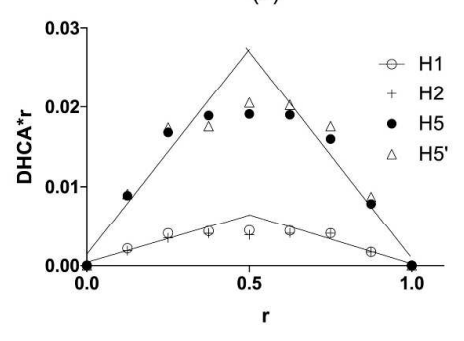

(4)

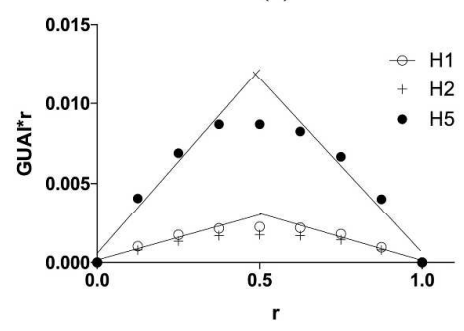

Figure SI3. Representation of the ligand: $\beta C D$ interaction (Job plots). [Ligand] $=0-810^{-3} \mathrm{M},[\beta C D]=8-010^{-3} \mathrm{M}$. Chemical shifts from $\beta C D$ protons $\mathrm{H} 1, \mathrm{H} 2$ and $\mathrm{H} 5$.

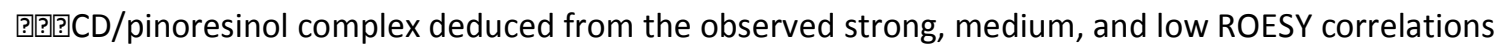
effects between protons $\mathrm{H}_{2}, \mathrm{H}_{5}, \mathrm{H}_{6}$ of ( \pm )-pinoresinol and protons $\mathrm{H}_{3}{ }_{3}, \mathrm{H}^{\prime}{ }_{5}, \mathrm{H}_{6}{ }_{6}$ of ?] $\mathrm{CD}$ is presented in the main text (Fig. 3). The proposed model is consolidated by strong interactions between protons $\mathrm{H}_{8}$ and $\mathrm{H}_{9}$ of ( \pm )-pinoresinol with protons $\mathrm{H}_{5}$ of 의? $\mathrm{CD}$ (red double arrows).

It should be pointed out that only unambiguous correlations were considered. Those with overlapping patterns potentially involving intramolecular interactions were discarded as for example in the coniferyl alcohol 2D-ROESY map (see red rectangle in panel B of Fig. SI.4).

A

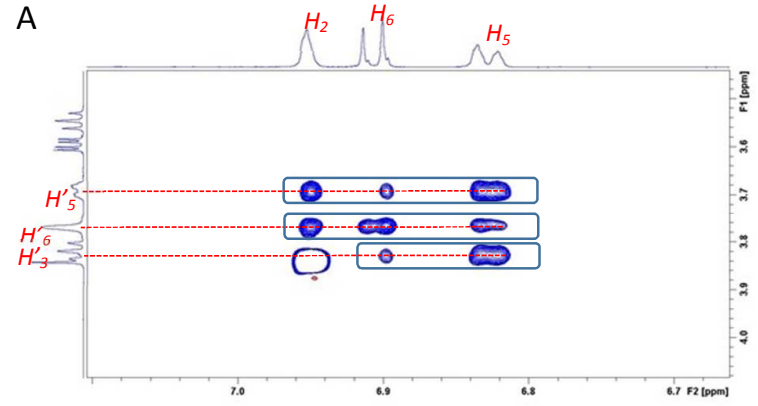

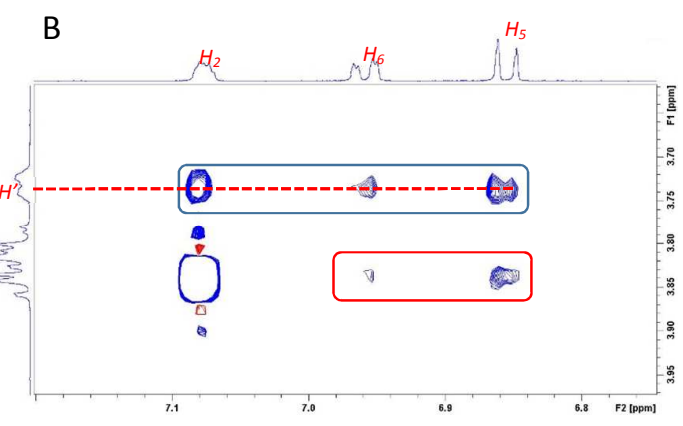

Figure S14. Fragments of ROESY spectra showing the intermolecular interactions between protons from ligands and proton from $\beta C D$. Panel $A$, ligand $=( \pm)$-pinoresinol; panel $B$, ligand $=$ coniferyl alcohol.

Interaction of dehydro di-coniferyl alcohol with a-CD led to splitting of some peaks in the 2D-ROESY spectrum indicating the presence of diastereoselective complexes that exhibit different cross peaks. The model proposed in Figure $\mathrm{SI} 5$ is based on strong interactions between $\mathrm{H}_{3}$ and $\mathrm{H}_{5}$ of aCD with the 
$\mathrm{H}_{15}$ of dehydro di-coniferyl alcohol (red double arrow). The orientation of dehydro di-coniferyl alcohol inside the $\beta C D$ cavity is based on the interaction of $\mathrm{H}_{6}^{\prime}$ and $\mathrm{H}_{3}$ with $\mathrm{H}_{16}$ and $\mathrm{H}_{9}$, respectively (green double arrows). However, this deep inclusion concerns only one of the two stereoisomers since the other $\mathrm{H}_{15}$ presents lower cross peaks. Therefore, only the complex with the deepest inclusion is illustrated in Figure SI5.
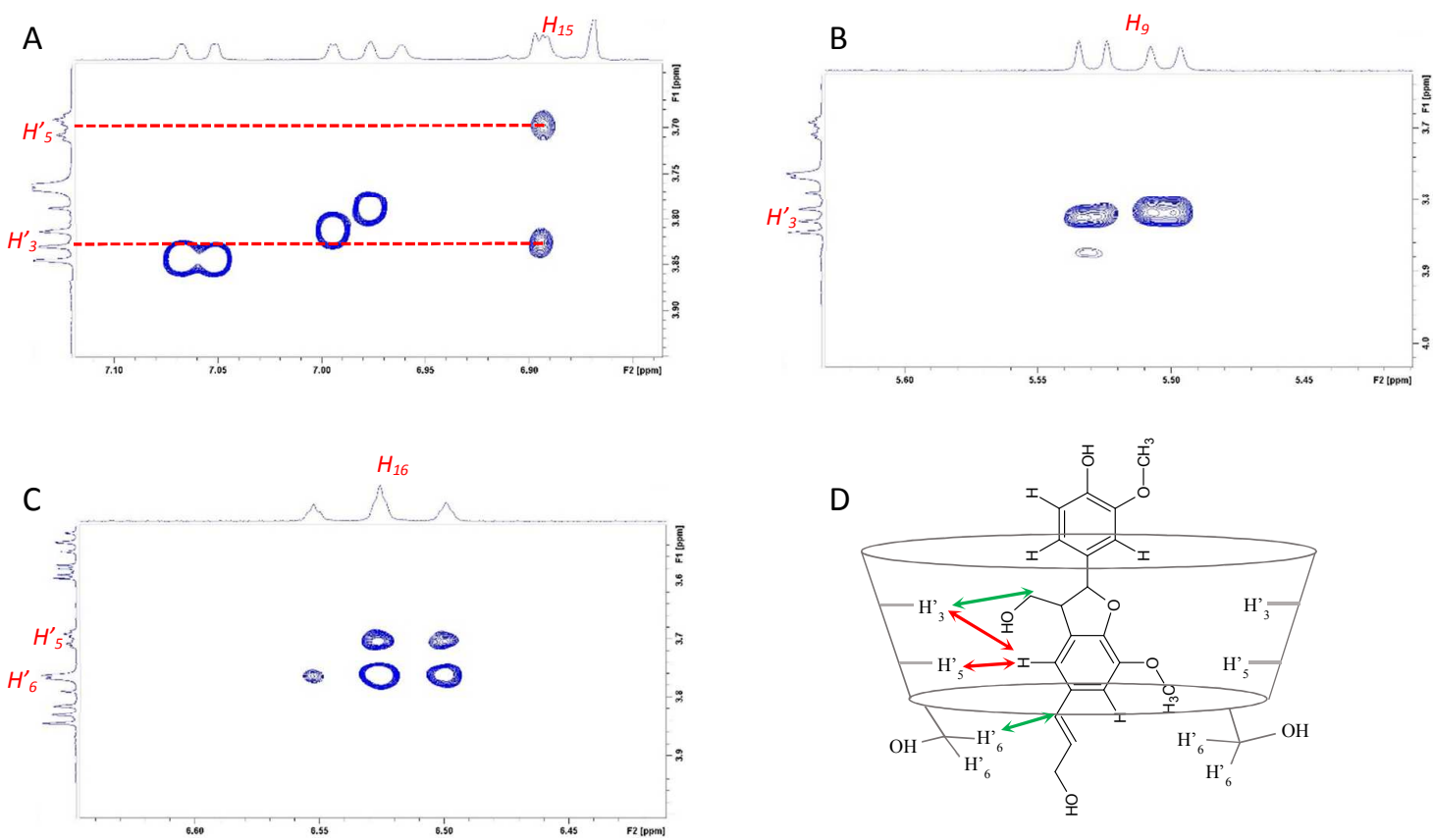

Figure SI5. Fragments of ROESY spectra showing the intermolecular interactions between protons from dehydro di-coniferyl alcohol and proton from $\beta C D$. Panel $A$, zoom in the interactions between the proton $\mathrm{H} 15$ of dehydro di-coniferyl alcohol and protons $\mathrm{H}^{\prime} 3$ and $\mathrm{H}^{\prime} 5$ of $\beta C D$; panel $\mathrm{B}$, zoom in the interactions between the proton $\mathrm{H} 9$ of dehydro di-coniferyl alcohol and protons $\mathrm{H}^{\prime} 3$ of $\beta C D$ (figure panel $\mathrm{D}$ ); panel $\mathrm{C}$, zoom in the interactions between the proton $\mathrm{H} 16$ of dehydro di-coniferyl alcohol and protons $\mathrm{H}^{\prime} 5$ and $\mathrm{H}^{\prime} 6$ of $\beta C D$ (figure panel $D$ ); panel $D$, scheme of the potential interactions; double arrows indicate spatial dipolar interactions classified from each CD proton: close (red), intermediate (green).

\section{Evolution of dimers production as function of the initial coniferyl alcohol concentration}

Oxidation of coniferyl alcohol was performed and analysed as described earlier in the text (see paragraph 2). A typical reaction mixture $(1 \mathrm{~mL})$ contained LAC3 $(5 \mathrm{U} / \mathrm{L})$ coniferyl alcohol $(2.5,5$ or 10 $10^{-3} \mathrm{M}$ ) in the presence (or absence) of $1210^{-3} \mathrm{M}$ of $\beta C D$.

( \pm )-dehydrodiconiferyl alcohols

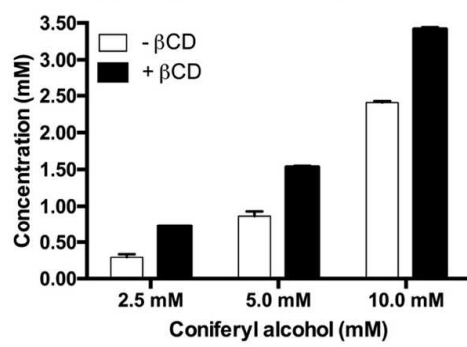

( \pm -pinoresinols

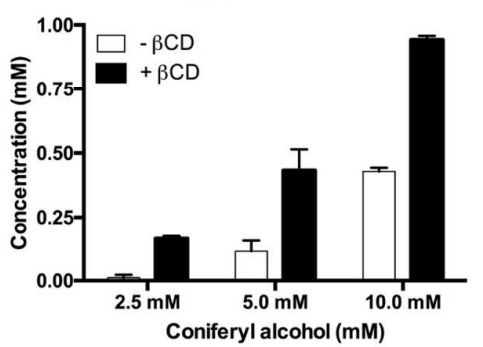

Figure SI6. Effects of a variable initial concentrations of coniferyl alcohol on the formation of dimers in the presence of $\beta C D$. 
1 Y. Mekmouche, S. M. Zhou, A. M. Cusano, E. Record, A. Lomascolo, V. Robert, A. J. Simaan, P. Rousselot-Pailley, S. Ullah, F. Chaspoul, T. Tron, J. Biosc. and Bioeng., 2014, 117, 25-27.

2 Kishimoto T., Takahashi N., Hamada M., Nakajima N., J. Agri. Food Chem., 2015, 63, 2277-2283.

3 W. Hinsberg, F. Houle. Kinetiscope ${ }^{\mathrm{TM}}$, a stochastic simulator v1.0.593.x64. C Columbia Hill Technical Consulting (2015)

4 Scott. R. L, Rec. Trav. Chem. Pays - Bas, 1956, 75, 787 - 789. 